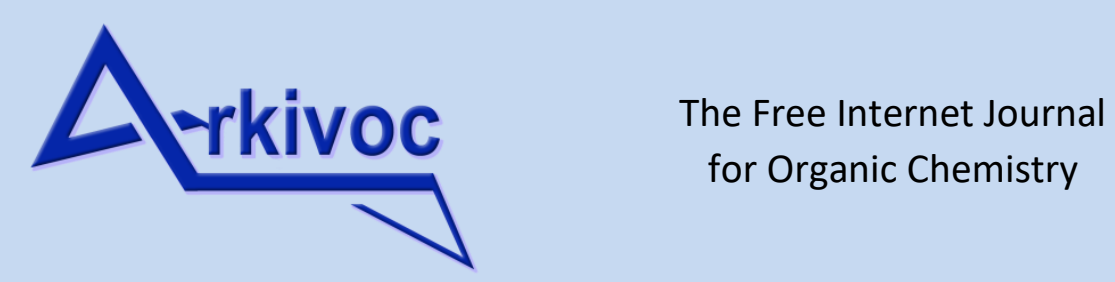

Archive for

Arkivoc 2020, part i, 0-0

Organic Chemistry

to be inserted by editorial office

\title{
Axially chiral phenolic derivatives of 8,8'-biquinolyl and 8-(naphth-1-yl)quinoline as platforms for discovery: The unfolding story of the 'azaBINOLs'
}

\author{
Paul R. Blakemore \\ Department of Chemistry, Oregon State University, Corvallis, OR 97330, USA \\ Email:paul.blakemore@oregonstate.edu
}

Dedicated to the memory of Professor James D. White (1935-2020)

Received mm-dd-yyyy

Accepted mm-dd-yyyy

Published on line mm-dd-yyyy

to be inserted by editorial office

\section{Abstract}

This account encapsulates the Author's interests in the chemistry of nitrogenous analogs of 1,1'-bi-2-naphthol (BINOL) in which either the 8-position ('8-azaBINOL') or both of the 8-and 8'-positions ('8,8'-diazaBINOL') of the binaphthyl have been formally replaced by $\mathrm{N}$-atoms. The consequences that such structural perturbations have on various kinetic (rate of enantiomerization), thermodynamic (basicity), and biological (anti-HIV activity) properties of the biaryl nucleus are elaborated and opportunities for the application of azaBINOLs in reaction catalysis are highlighted. The synthesis of parent azaBINOLs and their substituted derivatives is summarized, together with techniques to resolve these axially chiral compounds into their enantiomeric atropisomers.

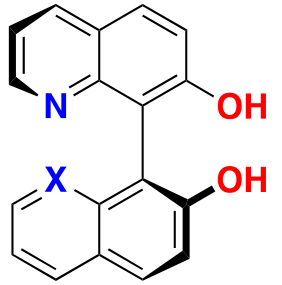

- $\mathrm{X}=\mathrm{CH}, \mathrm{N}: \mathrm{aza}-$ analogs of BINOL

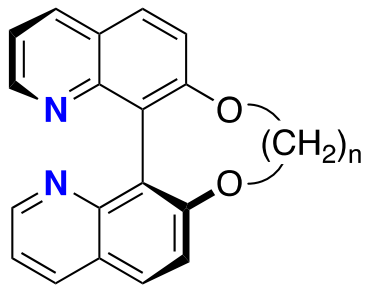

- conformation dependent $p K_{a H}$

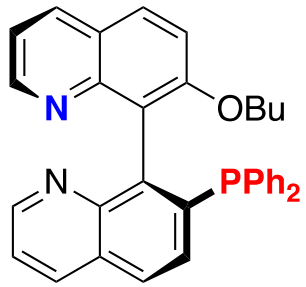

- chiral ligand for enantioselective Pd catalysis<smiles>CC(C)Oc1ccc2cccnc2c1-c1cccc2ccccc12</smiles>

- HIV-1 neutralization agent

Keywords: Axially chiral biaryls, enantiomerization kinetics, ambifunctional catalysis, HIV-1 neutralizations 


\section{Table of Contents}

1. Introduction

\subsection{General}

1.2 Notes on the motivation for the study of azaBINOLs

2. Synthesis of Parent AzaBINOLs and Their Derivatives

2.1 First generation synthesis of $8,8^{\prime}$-diazaBINOL and use of discovered anionic rearrangements to access $3,3^{\prime}$-disubstituted derivatives

2.2 Second generation synthesis of $8,8^{\prime}$-azaBINOL via $\mathrm{N}$-directed $\mathrm{CH}$-functionalization and its extension to 8-azaBINOL

3. Resolution and Configurational Stability of AzaBINOLs

3.1 Resolution of azaBINOLs and their chiroptical properties

3.2 Enantiomerization and racemization kinetics of azaBINOLs

4. Physical and Thermodynamic Properties of AzaBINOLs

4.1 Dependence of basicity on conformation and response of interannular dihedral angle to $\mathrm{pH}$

5. Promotion and Stereocontrol of Reaction Chemistry by AzaBINOLs

5.1 Silylcyanation of $\mathrm{C}=\mathrm{X}$ bonds catalyzed by a bissulfonamidyl 8,8'-diazaBINOL derivative

5.2 Enantioselective Suzuki-Miyaura reactions mediated by a phosphanyl $8,8^{\prime}$-azaBINOL derivative

5.3 Miscellaneous processes mediated by azaBINOL derivatives

5.3.1 Phase transfer catalysis with biquinolinium cations derived from $8,8^{\prime}$-diazaBINOL diethers

5.3.2 Direct amidation catalyzed by a boronic acid derivative of $8,8^{\prime}$-diazaBINOL

6. Emerging Biological Activity of AzaBINOLs

\subsection{Prefatory remarks}

6.2 Inhibition of HIV-1 RNase $\mathrm{H}$ activity by an ether derivative of 2'-deoxy-8-azaBINOL

7. Conclusions and Outlook

Acknowledgements

References

Author's Biography

\section{Introduction}

\subsection{General}

The introduction of subtle perturbations into a well-known molecular system may afford opportunities for the exploration of new and useful chemistry. Furthermore, such an exercise will most likely provide a context for the study of fundamental phenomena that could have impacts beyond whatever premise initially motivated an examination of the altered system in the first place. A case in point, and the subject of this account of an area of the Author's research, is the so-called 'azaBINOL' family of heterocyclic biaryl molecules; parent members of which, $\mathbf{2}$ and $\mathbf{3}$, are shown in Figure 1. AzaBINOLs are nitrogenous analogues of the well-known axially chiral biaryl ligand BINOL (1), ${ }^{1}$ in which one or two of the peri-CH moieties have been formally replaced by $\mathrm{N}$-atoms to reveal quinoline ring systems in place of naphthalenes. Some of the effects of this perturbation are obvious and could be readily anticipated, but others are not, and therein lies the reward common to the study of all new things. 
Herein, the history of the azaBINOL project is traced from its inception point as an essentially curiositydriven piece of research in the realm of enantioselective catalysis, to where it lies today after some quite unexpected findings have led to useful advances across a range of different areas, including: directed metallation chemistry, anionic rearrangements, interannular proximity effects, biaryl configurational stability, and HIV-1 neutralization. The interested reader is referred to the original azaBINOL publications cited herein for a full exposition of the topics presented with more extensive background literature. ${ }^{2-10}$ Throughout, atom positions within azaBINOL molecules are referred to in relation to BINOL numbering (see Figure 1); however, the numbering of any quinoline precursors conforms to the usual IUPAC convention.

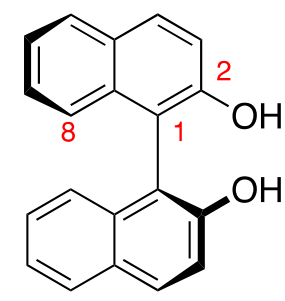

1

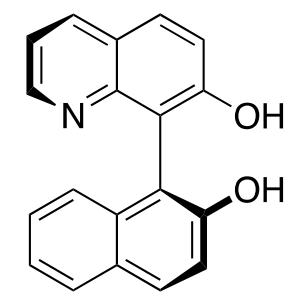

2<smiles>Oc1ccc2cccnc2c1-c1c(O)ccc2cccnc12</smiles>

3

Figure 1. BINOL (1, 1,1'-bi-2-naphth-2-ol) and parent members of the 'azaBINOL' family, referred to herein by a colloquial replacement nomenclature as 8-azaBINOL [2, 7-hydroxy-8-(2-hydroxynaphth-1-yl)quinoline] and 8,8'-diazaBINOL (3, 7,7'-dihydroxy-8,8'-biquinolyl). Molecules are depicted in (aS)configuration.

\subsection{Notes on the motivation for the study of azaBINOLs}

Some elaboration on the motivation to study azaBINOLs is warranted. At the time the azaBINOL project began (ca. 2000), interest arose in an axially chiral biaryl motif 4 containing 'ambifunctional quadrants,' each one a zone of potential catalytic activity by virtue of being flanked by a frustrated Lewis acid (LA)-Lewis base (LB) pair (Figure 2). Frustrated LA-LB pairs are known to promote a wide variety of reactions, ${ }^{11}$ and it was envisioned that the semi-rigid biaryl structure of $\mathbf{4}$ would serve the dual purpose of physically separating LA and LB sites while simultaneously offering a necessary chiral environment for enantioselective catalysis. Although several ambifunctional catalysts based on chiral biaryl frameworks were known at this time (e.g., 7 and 8), ${ }^{12,13}$ none shared the topology of motif 4 , which we felt may offer unique reactivity and be worthy of further study. Conceivably, a construct such as 4 could catalyze enantioselective bond formation between pro-nucleophiles and pro-electrophiles within its ambifunctional quadrants (as generically illustrated) and perhaps also enable atom-transfer reactions from enoid species to unsaturated bonds and other moieties. 


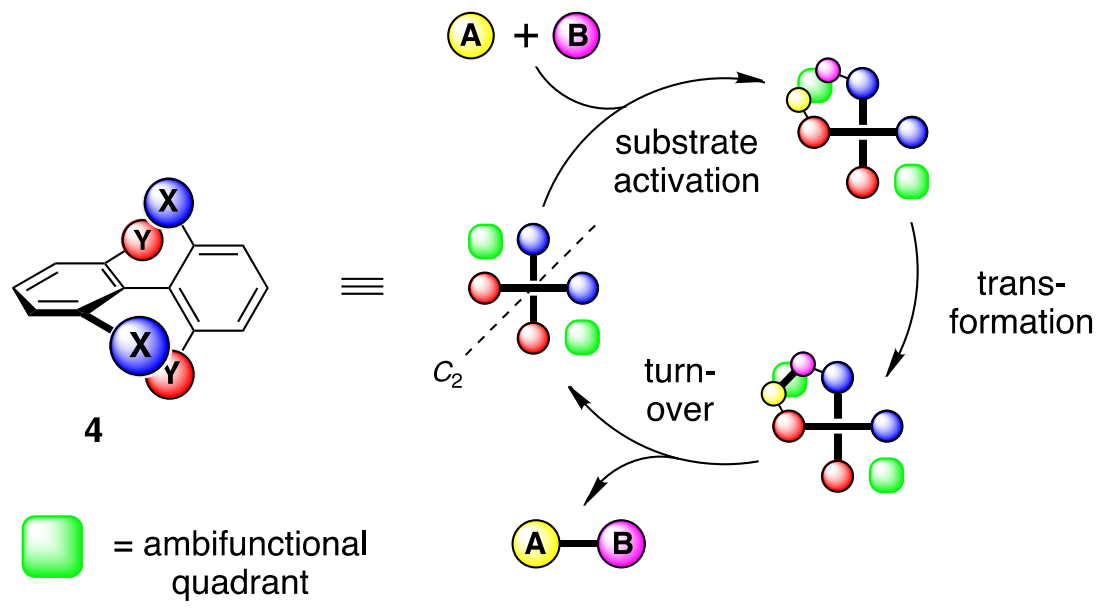

Figure 2. A notional ambifunctional catalyst system 4 based on the location of frustrated Lewis acid-Lewis base pairs within an axially chiral $C_{2}$-symmetric biaryl template. $X=$ Lewis base, $Y=$ Lewis acid, $A=$ proelectrophile, $\mathrm{B}=$ pro-nucleophile.

8,8'-DiazaBINOLs with additional coordinating substituents at $\mathrm{C} 3$ and $\mathrm{C}^{\prime}$ ' to form $\mathrm{C} 2 / \mathrm{C} 3$ and $\mathrm{C2}^{\prime} / \mathrm{C}^{\prime}$ chelates with suitable metal residues (e.g., $\mathrm{MgX}_{2}, \mathrm{BX}_{3}, \mathrm{AlX}_{3}, \mathrm{TiX}_{4}$ ), such as bissulfonamide 5 (Figure 3), were identified to be among the simplest molecules that could lead to a physical embodiment of scaffold 4 . Speciation of metal residues by $\mathbf{5}$ in the appropriate manner would give a metal complex (6) containing filled ( $\mathrm{N}$-centered $\mathrm{sp}^{2}$-lone pairs) and vacant orbitals (metal centered $\mathrm{p}$-orbitals) unable to directly interact with each other (at least, in an intramolecular sense) because of the skewed orthogonality of their positions in space. Adding to the allure of this plan was the structural similarity of the requisite precursor molecules involved to BINOL (1), and it was felt that the mass of collected knowledge on BINOL could be leveraged throughout our study. Thus, the azaBINOL project began with a focus on preparing molecules such as $\mathbf{5}$ and examining derived metal complexes as enantioselective ambifunctional catalysts. However, as documented herein, the analogy between 8,8'-diazaBINOL (3) and BINOL (1) was found to extend only so far and during the course of our investigations our attention was increasingly drawn to explore how biquinolyls, and related mixed naphthylquinoline biaryls, differ from the better known binaphthyls. Also, as is invariably the case when novel chemical entities are prepared, new possibilities for azaBINOLs became evident as the project moved forward and our thinking about them grew to be more sophisticated.

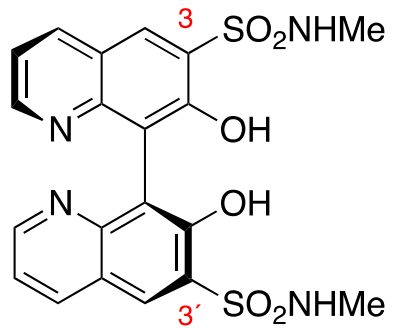

5

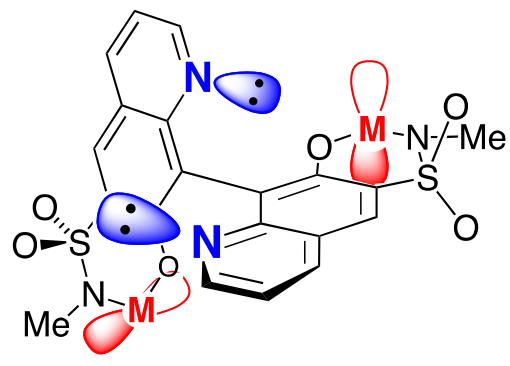

6

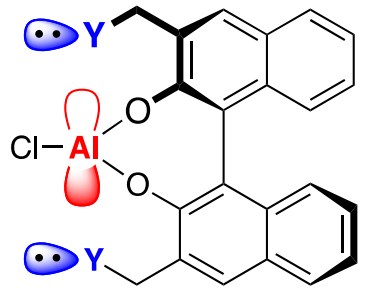

$7 \mathrm{Y}=\mathrm{P}(\mathrm{O}) \mathrm{Ar}_{2}$ Shibasaki

$8 \mathrm{Y}=\mathrm{NEt}_{2} \quad$ Nájera

Figure 3. A 3,3'-bissulfonamidyl derivative of $8,8^{\prime}$-diazaBINOL (5) as a putative precursor to an axially chiral ambifunctional catalyst (6) representing motif 4 and two previously established ambifunctional catalysts based on BINOL derivatives ( $\mathbf{7}$ and $\mathbf{8}){ }^{12,13}$ 


\section{Synthesis of Parent AzaBINOLs and Their Derivatives}

Synthesis of 8,8'-diazaBINOL (3) in racemic form and its subsequent advancement to bissulfonamide $\mathbf{5}$ was the first objective. Our forays in this endeavor were wholly unsuccessful because they were based on flawed logic; viz, that $\mathbf{3}$ could be obtained in an analogous fashion to its all carbocyclic congener BINOL (1) by oxidative phenolic coupling of 7-hydroxyquinoline (9), and that conversion of $\mathbf{3}$ to $\mathbf{5}$ could be achieved in high yield by direct chlorosulfonation/amination (Scheme 1). A survey of many different kinds of oxidants, all of which are known to successfully convert 2-naphthol to BINOL, identified none that could transform 9 to its oxidized dimeric form 3 (in general, no reaction was observed). ${ }^{2}$ When 8,8'-diazaBINOL (3) was later obtained by a different means, its exposure to hot excess chlorosulfonic acid followed by treatment with methylamine, gave 5 in no more than trace quantities ( $<5 \%$ yield). Neither result is surprising in retrospect when considering the very different character of 2-naphthol (electron-rich, non-basic) versus 7-hydroxyquinoline (9) (electron-poor arene containing a basic heteroatom). Although a quinoline nucleus is not as easily oxidized as a naphthalene system, nor as facile in its electrophilic substitution reactions, much other unique chemistry is possible, indeed, to such an extent as to make the azaBINOLs far more amenable to derivatization than BINOLs.

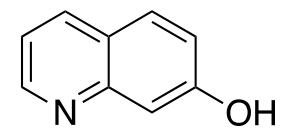

9
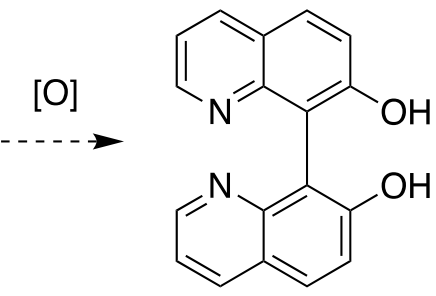

3

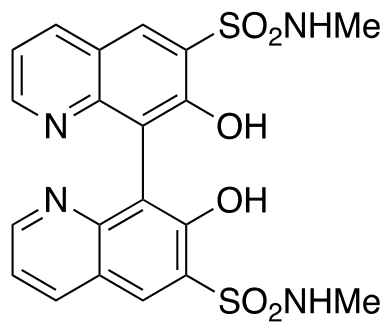

5

Scheme 1. An unsuccessful plan for a concise synthesis of bissulfonamide 5 from 7-hydroxyquinoline (9) that draws a false parallel to the reactivity of 2-naphthol and that expected for BINOL (1).

Two different successful approaches (described below) were developed to access 8,8'-diazaBINOL (3), both rational in their design and the second relying on modern $\mathrm{CH}$ functionalization chemistry; however, the route ultimately identified to generate bissulfonamide $\mathbf{5}$ is far from obvious and it illustrates the role that reaction discovery can play in target directed synthesis efforts.

\subsection{First generation synthesis of $8,8^{\prime}$-diazaBINOL and use of discovered anionic rearrangements to access 3, $3^{\prime}$-disubstituted derivatives}

The first successful approach to $8,8^{\prime}$-diazaBINOL $(3)^{2}$ was based on directed ortho-metallation chemistry and it took advantage of the known propensity of the $\mathrm{N}, \mathrm{N}$-dimethyl carbamate derivative of 7-hydroxyquinoline (10) to selectively lithiate at C8 (Scheme 2). ${ }^{14}$ With the C8-position activated as a carbanion (organolithium 11), the desired biquinolyl 13 was generated initially by iodination followed by Ullmann-type biaryl coupling of the intermediate 8-iodoquinoline 12. Soon after, it was discovered that a high yielding and more step efficient entry to 13 was available by direct anhydrous $\mathrm{FeCl}_{3}$ mediated oxidative coupling of the organolithium. Simple saponification of biscarbamate $\mathbf{1 3}$ gave $8,8^{\prime}$-diazaBINOL (3) as a pale yellow powder sparingly soluble in most common organic solvents, but with high solubility in dipolar aprotic solvents (DMSO and DMF) and in water. Recrystallization of $\mathbf{3}$ from $\mathrm{MeOH}$ gave a disolvate as yellow plates (mpt. $258-260{ }^{\circ} \mathrm{C}$ ), X-ray diffraction (XRD) analysis of which revealed a preference for a transoid conformation in the solid state (Figure 4). ${ }^{2} \mathrm{~A}$ potentially useful sterically hindered variant of 3,7,7'-di-tert-butyl-8,8'-diazaBINOL (14), akin to an axially chiral version of 2,6-di-tert-butyl-4-methylpyridine, was generated from 13 by facile addition of $t$-BuLi and aerial oxidation, 
followed by saponification in air. ${ }^{4}$ By contrast to the parent diol $\mathbf{3}$, alkylated azaBINOL $\mathbf{1 4}$ readily dissolves in a range of organic solvents (e.g., THF, $\mathrm{CH}_{2} \mathrm{Cl}_{2}, \mathrm{MeOH}$ ) and XRD analysis of crystals obtained from $\mathrm{MeOH}$ showed much heightened transoid character with evidence for interannular $\mathrm{H}$-bonds between the head-to-tail oriented quinol units (Figure 4). ${ }^{4}$
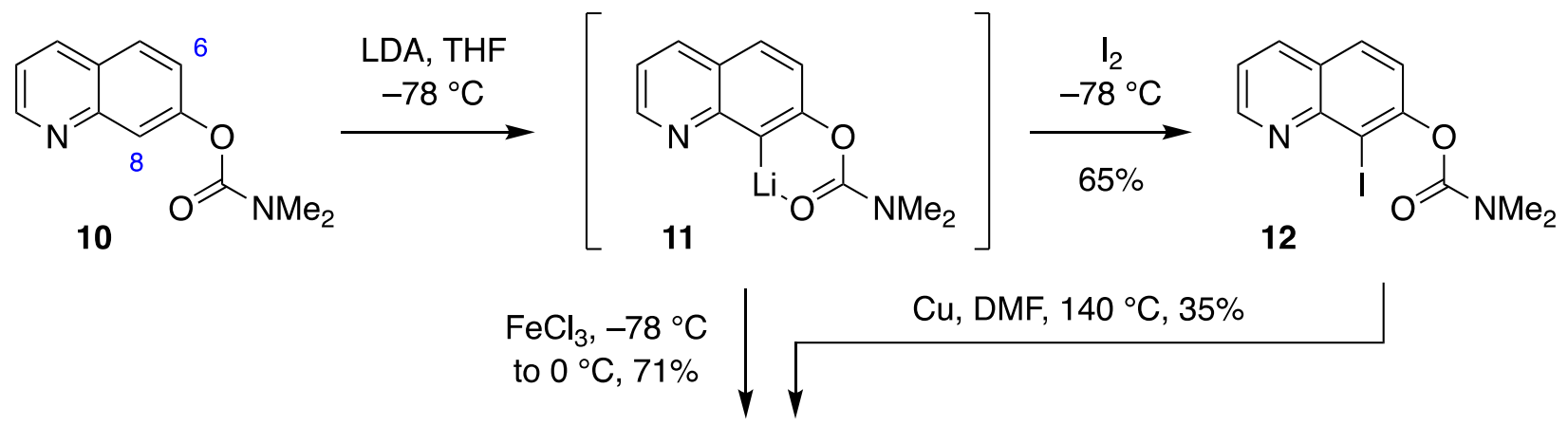<smiles>Oc1ccc2cccnc2c1-c1c(O)ccc2cccnc12</smiles>

3

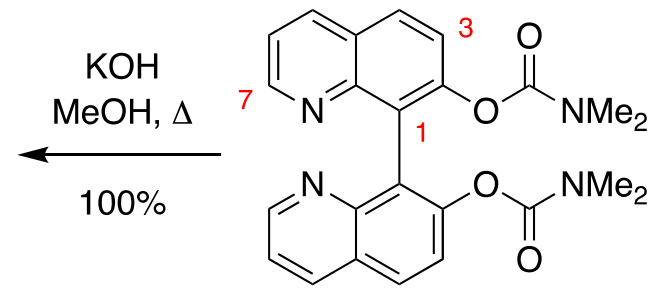

13 (a) $t$-BuLi, THF $-78{ }^{\circ} \mathrm{C}, 69 \%$

(b) $\mathrm{KOH}, \mathrm{MeOH}$ air, $\Delta, 99 \%$<smiles>CC(C)(C)c1ccc2ccc(O)c(-c3c(O)ccc4ccc(C(C)(C)C)nc34)c2n1</smiles>

14

Scheme 2. First generation syntheses of $8,8^{\prime}$-diazaBINOL (3) and 7,7'-di-tert-butyl-8, $8^{\prime}$-diazaBINOL (14) via directed ortho-metallation of a carbamate derivative of 7-hydroxyquinoline (10). ${ }^{2,4}$

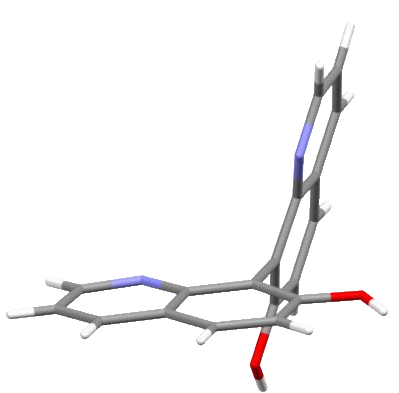

3

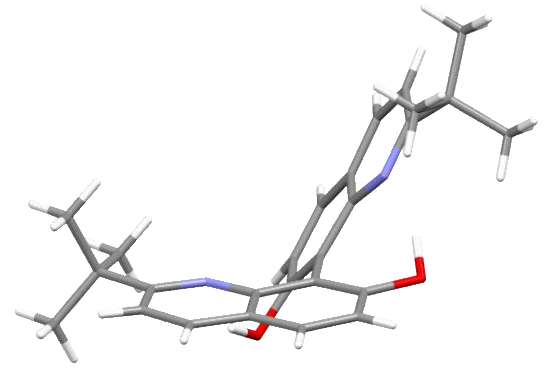

14

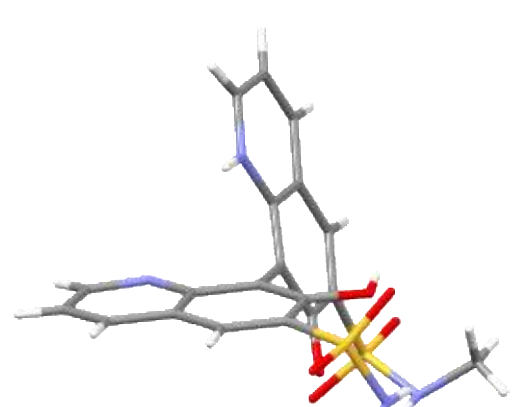

5

Figure 4. X-ray crystal structures for 8,8'-diazaBINOL (3), 7,7'-di-tert-butyl-8,8'-diazaBINOL (14), and 3,3'-bis(methylaminosulfonyl)-8, $8^{\prime}$-diazaBINOL (5). Detailed notes concerning XRD analyses and relevant CIFs are available in the original publications. ${ }^{2,4,7}$

With a viable approach to the 8,8'-diazaBINOL scaffold realized, attention focused on further advancement to the actual target of initial interest, bissulfonamide $\mathbf{5}$. As mentioned above, direct chlorosulfonation of $\mathbf{3}$ was not effective; however, with ortho-metallation activating groups present at C2 and C2' of the azaBINOL nucleus of 13, it was an obvious tactic to employ them again in the task of introducing substituents at $\mathrm{C} 3$ and $\mathrm{C}^{\prime}$. In the event, treatment of 13 with LDA at $-78{ }^{\circ} \mathrm{C}$ resulted in a facile anionic orthoFries rearrangement ${ }^{15}$ of one of the carbamoyl moieties, but since our goal was the installation of metalcoordinating substructure at $\mathrm{C} 3$ and $\mathrm{C3}^{\prime}$ anyway, we recognized the rearrangement as fortuitous. After some 
optimization it proved possible to migrate both carbamoyl groups, albeit in modest yield, to arrive at bisamide 15 (Scheme 3). This compound, of interest in its own right as an appropriate ligand precursor to a motif 4 , was advanced to other potential catalyst precursors, 16 and 17, by the illustrated standard amide reduction protocols. $^{\mathrm{i}}$<smiles>CNC(=O)Oc1ccc2cccnc2c1-c1c(OC(=O)NC)ccc2cccnc12</smiles>

13

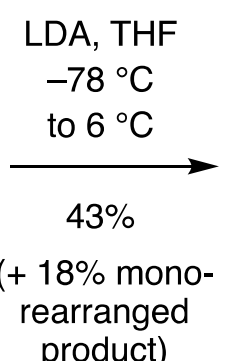

product)<smiles>CNC(=O)c1cc2cccnc2c(-c2c(O)c(C(=O)N(C)C)cc3cccnc23)c1O</smiles>

15

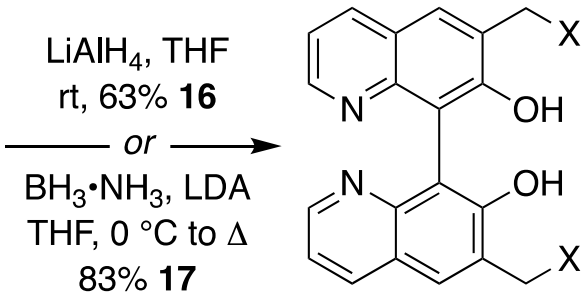

16, $\mathrm{X}=\mathrm{NMe}_{2}$

$17, \mathrm{X}=\mathrm{OH}$

Scheme 3. Double anionic ortho-Fries rearrangement from biscarbamate 13 and advancement of resulting bisamide $15 .^{2}$

The modest efficiency of the second anionic Fries rearrangement involved in the conversion of $\mathbf{1 3}$ to $\mathbf{1 5}$ was attributed to the difficulty of establishing the necessary complex-induced proximity effect $(\mathrm{CIPE})^{17}$ to achieve deprotonation at C3' following the first rearrangement because, at this stage, the emergent lithium alkoxide at C2 likely competes with LDA for coordination of the remaining carbamate at C2'. In seeking a higher yielding synthesis of $\mathbf{1 5}$, it was felt that a strategic reversal in biquinolyl synthesis and carbamate rearrangement steps would pay dividends; viz, the anionic ortho-Fries rearrangement should be effected on 8iodoquinoline 12 and then the resulting product converted to $\mathbf{1 5}$ by Ullmann coupling. In the event, the anionic Fries rearrangement from 12 gave the intended amide $\mathbf{2 0}$ (confirmed by XRD analysis) when the putative 6-lithio-8-iodoquinoline 18 generated from 12 with LDA at $-78{ }^{\circ} \mathrm{C}$, was allowed to warm to $0{ }^{\circ} \mathrm{C}$ before protonolysis (Scheme 4$).^{2}$

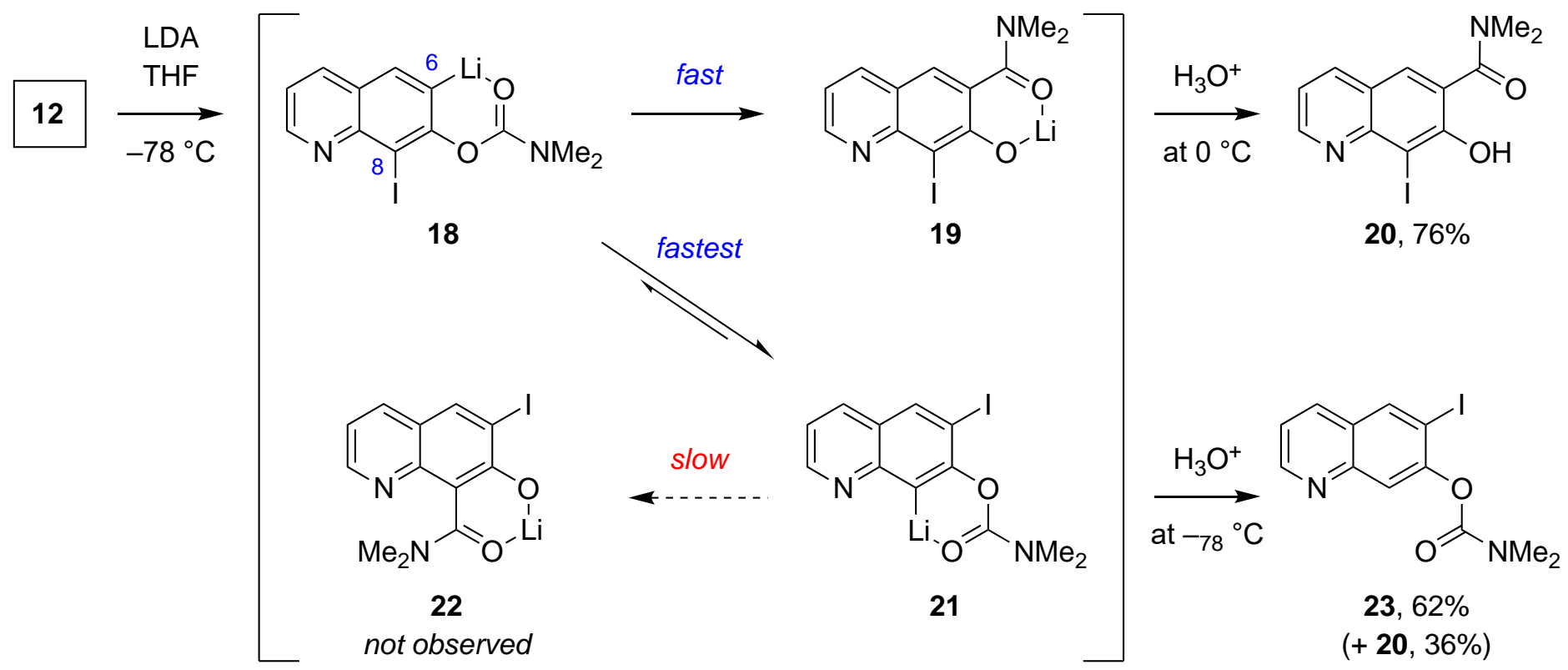

Scheme 4. Competing anionic rearrangements of iodoquinolyllithium $18 .^{2}$ 
It transpired that reductive coupling of $\mathbf{2 0}$ was not successful, but a closer examination of the process that generated this amide led to the development of a more efficient approach to access 3,3'-disubstituted 8,8'diazaBINOLs than any of those that we had previously designed. In a key experiment, quenching the lithiation reaction of $\mathbf{1 2}$ at low temperature was observed to afford 6-iodoquinoline 23, the result of a halogen-dance rearrangement. ${ }^{18}$ The accumulated data are explicable as follows. Upon generation, 18 enters into a dynamic equilibrium with its Li/I transposed regioisomer 21, presumably by virtue of the usual ionic chain mechanism for $1, n(n>2)$ halogen-dance reactions and so involving an intermediate diiodide. ${ }^{18}$ Although 6-iodo-8-lithioquinoline $\mathbf{2 1}$ is the thermodynamically more stable carbanion of the pair $\mathbf{1 8}$ and 21, it is a kinetically less competent organolithium than 8-iodo-6-lithioquinoline $\mathbf{1 8}$ for the ensuing anionic ortho-Fries rearrangement. Thus, as the temperature is increased, a Curtin-Hammett scenario operates wherein the thermodynamically less stable isomer of the halogen-dance equilibrium (18) is irreversibly siphoned-off to give alkoxide 19 but the anionic ortho-Fries rearrangement product from $\mathbf{2 1}$ (alkoxyamide 22) is not formed. A novel tandem halogendance/oxidative coupling process was immediately devised to take advantage of the observations and to gain a general entry to 3,3'-disubstituted 8,8'-diazaBINOLs (Scheme 5). As illustrated, low temperature lithiation of the $\mathrm{N}, \mathrm{N}$-diethylcarbamate congener of $\mathbf{1 2}(\mathbf{1 2})$ followed by addition of anhydrous $\mathrm{FeCl}_{3}$ to splice together the intermediate 6-iodo-8-lithioquinoline, delivers 3,3'-diiodo-8,8'-diazaBINOL biscarbamate 24 directly. Herein, use of the $\mathrm{N}, \mathrm{N}$-diethyl- (12') rather than the $\mathrm{N}, \mathrm{N}$-dimethyl- (12) carbamate derivative serves to suppress the now unwanted anionic ortho-Fries rearrangement. Given the synthetic versatility of aryl iodides, one may regard 24 as a precursor to almost any 3,3'-disubstituted 8,8'-diazaBINOL of interest and its advancement to the long sought after bissulfonamide 5 was achieved without incident (see Figure 4 for X-ray structure). ${ }^{2}$

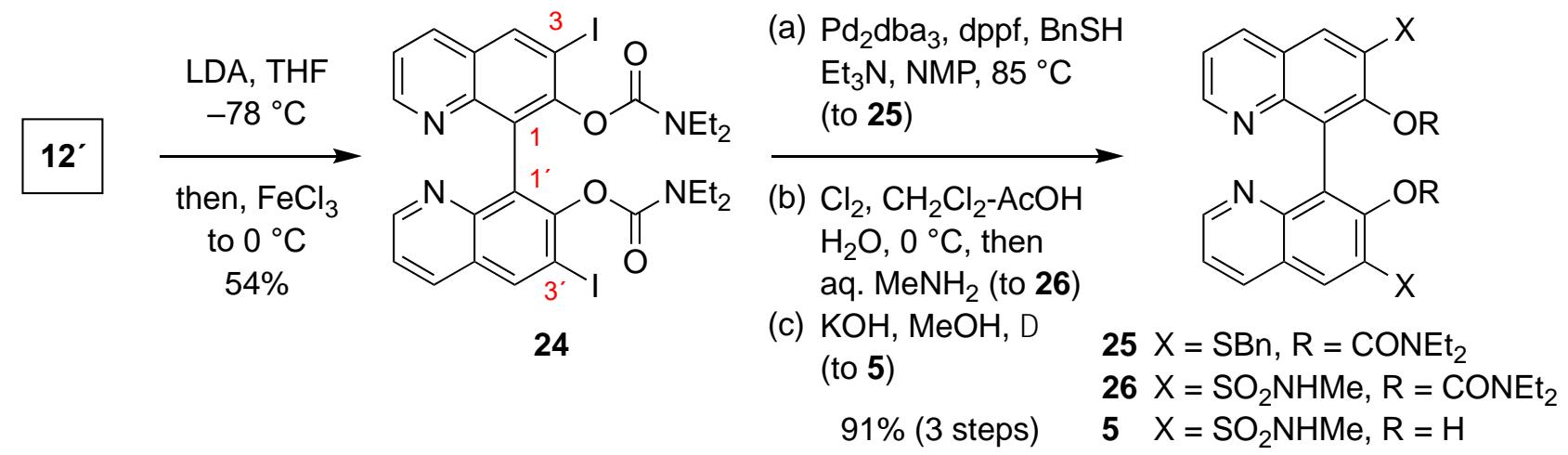

Scheme 5. Tandem halogen-dance / oxidative coupling from a 7-carbamoyloxy-8-iodoquinoline (12') to realize an efficient entry to $3,3^{\prime}$-disubstituted $8,8^{\prime}$-diazaBINOLs. ${ }^{2}$

\subsection{Second generation synthesis of $8,8^{\prime}$-azaBINOL via $\mathbf{N}$-directed $\mathbf{C H}$-functionalization and its extension to 8-azaBINOL}

Although satisfactory in many ways, the first approach to 8,8'-diazaBINOL (3) as described above was viewed as less than ideal because of its overall length and reliance on 7-hydroxyquinoline (9) as an intermediate. This simple quinol is expensive and it has limited commercial availability due to the difficulty of its preparation. For example, the direct Skraup synthesis ${ }^{19}$ from 3-aminophenol (27) is low yielding because it is complicated by a lack of regiocontrol (5-hydroxyquinoline is co-generated) and obtaining satisfactorily pure samples of $\mathbf{9}$ from the resinous crude material obtained is very challenging. Of the alternate possibilities, Fukuyama's ingenious synthesis of 7-hydroxyquinoline (9) via conjugate addition of the $\mathrm{N}$-tosyl derivative of 3-aminophenol (28) to acrolein (29) was our preferred entry to this critical material; however, four steps are needed to access $\mathbf{9}$ using this approach (Scheme 6). ${ }^{20}$ All told, at seven steps long overall and necessitating several chromatographic 
purification stages, the first generation synthesis of $8,8^{\prime}$-diazaBINOL $(3)^{2}$ via 7-hydroxy-quinoline (9) was regarded as too arduous to allow for unfettered development of azaBINOL chemistry and a more efficient entry to this biaryl family was sought. ${ }^{6}$

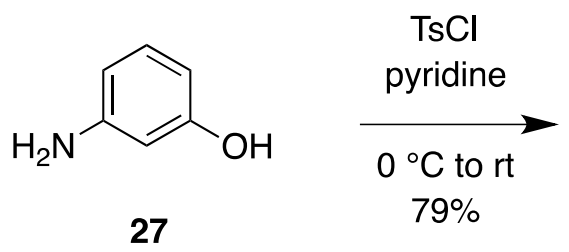

27<smiles>CNc1cccc(O)c1</smiles>

28

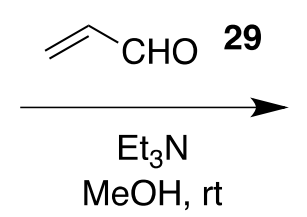

$\mathrm{MeOH}, \mathrm{rt}$<smiles>[13CH3]N(CCC=O)c1cccc(O)c1</smiles>

30
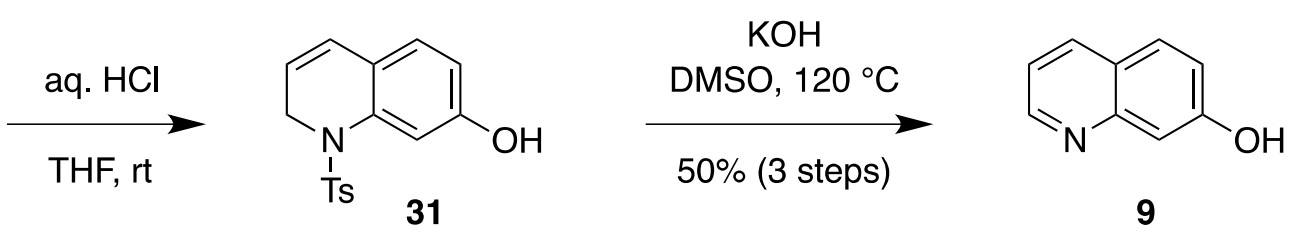

Scheme 6. Fukuyama's four-step synthesis of 7-hydroxyquinoline (9). ${ }^{20}$

Contemporaneous advances in $\mathrm{CH}$ functionalization chemistry by Sanford, ${ }^{21}$ among others, ${ }^{22}$ predicated that an alternate route to $8,8^{\prime}$-diazaBINOLs 33 was potentially available by $N$-directed $\mathrm{Pd}(\mathrm{II})$ mediated oxidation of biquinoyl 32 (Scheme 7). During such a transformation, in which the N8-atom of the protoazaBINOL serves to direct oxidation of the $\mathrm{C}^{\prime}{ }^{\prime} \mathrm{CH}$-bond while the $\mathrm{N} 8$ '-atom does likewise for the $\mathrm{CH}$-bond located at $\mathrm{C} 2$, an initially tropos (freely rotating) and essentially achiral biaryl $\mathbf{3 2}$ is converted to an atropos and axially chiral biaryl 33. Given the likely ease of accessing 32, this process was regarded as attractive; furthermore, such a reaction could conceivably be rendered enantioselective by the use of an appropriate scalemic Pd(II) complex.

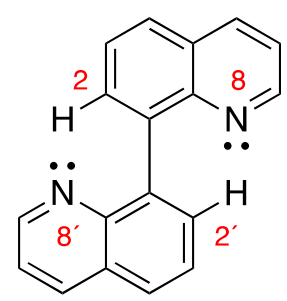

32

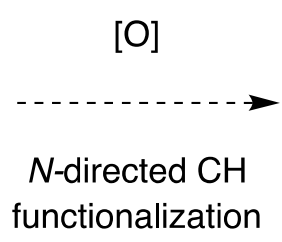

tropos - achiral

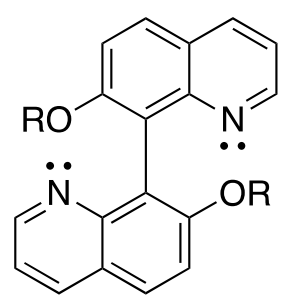

33

atropos - chiral

Scheme 7. A concise entry to 8,8'-diazaBINOLs 33 by $N$-directed $\mathrm{CH}$ functionalization of biquinolyl 32.

The plan outlined above was successfully executed (Scheme 8 ). ${ }^{6}$ Of various approaches evaluated, a practical synthesis of biquinolyl 32 was best achieved by a $\mathrm{Ni}(0)$-mediated coupling of 8-chloroquinoline (35), ${ }^{23}$ which was obtained by the high yielding Skraup reaction of 2-chloroaniline (34). After extensive optimization of reaction variables, it was discovered that the Sanford oxidation of $\mathbf{3 2}$ performed very well and the diacetate of 8,8'-diazaBINOL (37) or the monoacetate of deoxy-8,8'-diazaBINOL (36) could be produced as desired based on the stoichiometry of terminal oxidant $\left[\mathrm{Phl}(\mathrm{OAc})_{2}\right]$ employed. Straightforward saponification of the esters gave the corresponding quinols in quantitative yield. Adding to the attractiveness of this now four step entry to $8,8^{\prime}$-diazaBINOL (3) is the fact that the whole sequence can be successfully implemented without recourse to chromatographic purification. ${ }^{6}$ An enantioselective variant awaits its realization. 


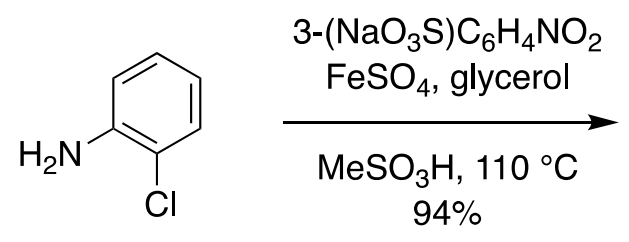

34<smiles>Clc1cccc2cccnc12</smiles>

35

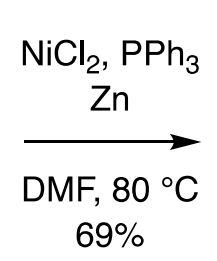

$69 \%$<smiles>c1cnc2c(-c3cccc4cccnc34)cccc2c1</smiles>

32

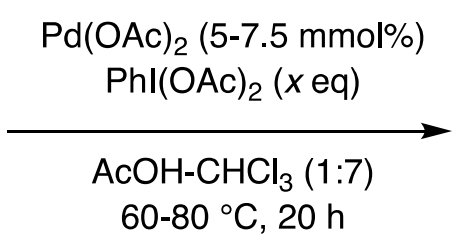

$x=1.2 \mathrm{eq}$
$x=2.5 \mathrm{eq}$

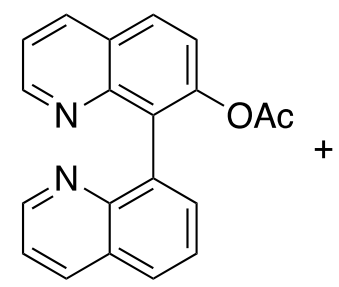

36

$68 \%$ $18 \%$<smiles>CC(=O)Oc1ccc2cccnc2c1-c1c(OC(C)=O)ccc2cccnc12</smiles>

37

$11 \%$

$76 \%$

Scheme 8. Synthesis of biquinolyl 32 and its advancement to diacetyl 8,8'-diazaBINOL (37) by double $N$ directed $\mathrm{CH}$-functionalization using the Sanford oxidation. ${ }^{6}$

Extension of the same approach to 8 -azaBINOL (2) was straightforward (Scheme 9). ${ }^{9}$ This hybrid naphthylquinoline biaryl compound became of interest to us later on as a more soluble member of the azaBINOL family with superior configurational stability to $\mathbf{3}$ (see Section 3.2). To access the requisite precursor for the Sanford oxidation in this case (naphthylquinoline 38), 8-iodoquinolinyl carbamate 12', used in the earlier tandem halogen-dance/oxidative dimerization, was coupled with 1-naphthylboronic acid via a Suzuki-Miyaura crosscoupling reaction. ${ }^{24}$ The desired diol 2 was obtained as a microcrystalline material in high yield from 38 by $N$ directed $\mathrm{CH}$-functionalization as indicated followed by saponification. Diol $\mathbf{2}$ is indeed more soluble than its polar congener $\mathbf{3}$, and it was found to readily dissolve in a number of common organic solvents, such as THF, toluene, and $\mathrm{CH}_{2} \mathrm{Cl}_{2} .{ }^{9}$ Samanta and coworkers recently realized an elegant alternative synthesis of 2 via Rh(III)catalyzed C8-arylation of 7-methoxyquinoline- $N$-oxide with diazonaphthalen-2(1H)-one. ${ }^{25}$

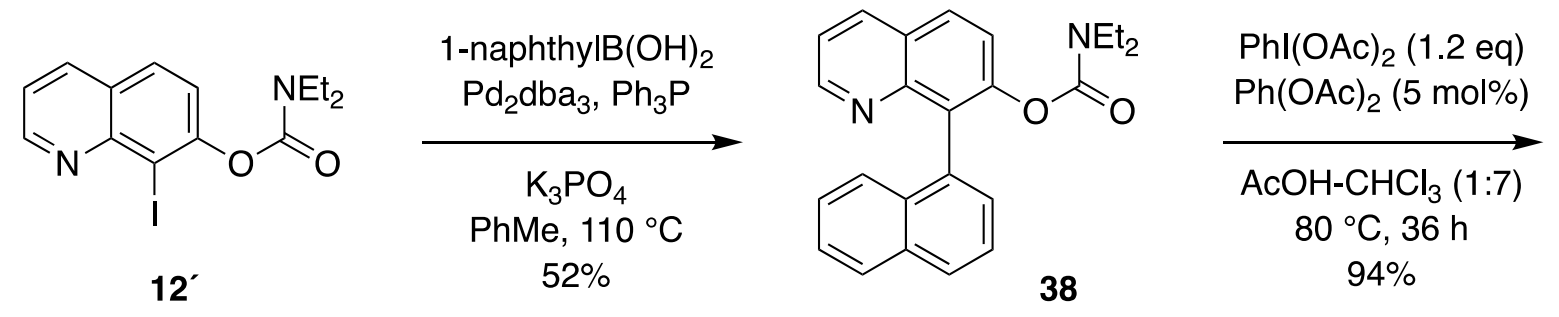<smiles>CCNC(=O)Oc1ccc2cccnc2c1-c1c(OC(C)=O)ccc2ccccc12</smiles>

39

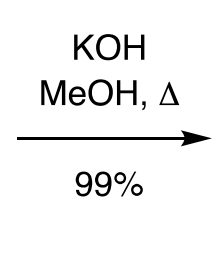

Scheme 9. Synthesis of 8-azaBINOL (2) via Sanford oxidation of 2'-deoxy-8-azaBINOL carbamate 38. 


\section{Resolution and Configurational Stability of AzaBINOLs}

For a given azaBINOL derivative to have potential applications in an area such as enantioselective synthesis or chiral recognition, etc., it is important for a method to exist to obtain it in an enantioenriched form and for the configurational stability of the resulting scalemic material to be appreciated and understood. The well known 'axial chirality' of biaryl molecules like the azaBINOLs is due to restricted rotation about the interannular bond giving rise to the possibility of a meaningful separate existence for the enantiomeric atropisomers. Chirality conferred solely by virtue of atropisomerism is not the concrete property that one would like it to be; thus, rather than being able to give a simple 'Yes' or a 'No' answer to the question of "Is this molecule chiral?", one must instead refer the enquirer to the limits of the compound's configurational stability (e.g., its racemization half-life, $\tau_{1 / 2 \text {-rac }}$ ) under a given set of conditions. The simplest pathways to consider for the configurational inversion of BINOL and azaBINOL derivatives are rotations about the interannular bond via either syn- or antitype eclipsed conformational transition states $\mathbf{4 1}$ (Figure 5); however, in the case of free phenolic compounds, tautomerization to one of several possible keto forms may be implicated in the overall racemization process. In this section, strategies to achieve the resolution of azaBINOL derivatives will be presented alongside determination of the enantiomerization/racemization kinetics for a number of key compounds. Regarding the parent diol molecules, $\mathbf{1}, \mathbf{2}$, and $\mathbf{3}$, and considering the simple enantiomerization pathways shown below, one may surmise that BINOL (1) is the most configurationally stable of the three compounds, and 8,8'-diaza-BINOL (3) the least, on the basis that a $\mathrm{C}-\mathrm{H}$ bond is presumably more sterically encumbering than an $\mathrm{N}$-atom lonepair. While this reasoning does predict the correct order for configurational stability within the series (as $\mathbf{1} \mathbf{2}$ >3), enantiomerization kinetic experiments suggest that it is likely for the wrong reason (vide infra).

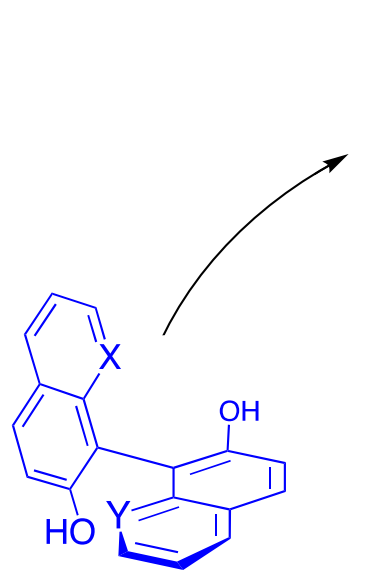

(aS)-40

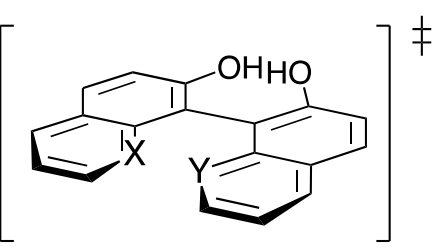

syn-41

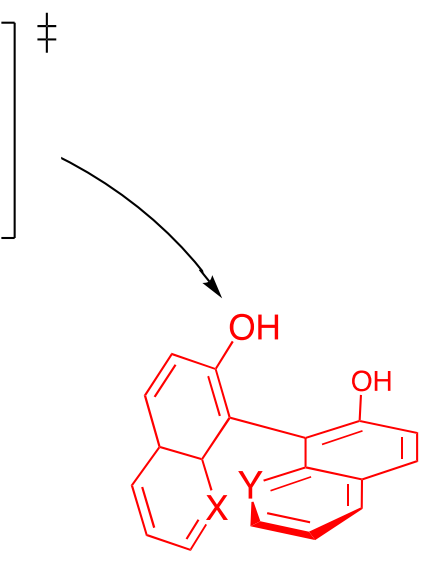

$(\mathrm{a} R)-40$
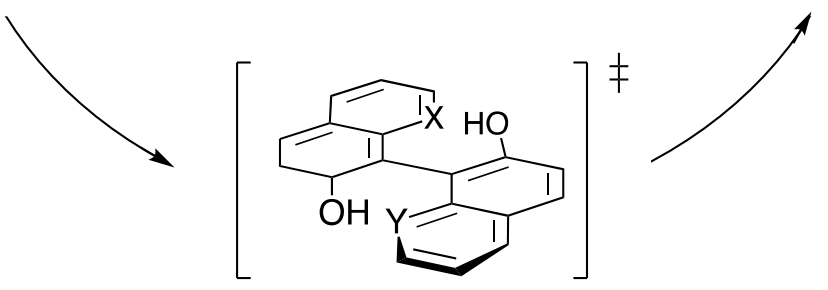

anti-41

Figure 5. Simple pathways for enantiomerization of BINOL $(X=Y=C H)$ and azaBINOLs $(X=N, Y=N$ or $C H)$ involving achiral syn or anti transition states $(\mathbf{4 1})$ accessed by interannular bond rotation. 


\subsection{Resolution of azaBINOLs and their chiroptical properties}

It has generally been found that methods developed for the resolution of BINOL (1) are also effective when applied to the resolution of the isostructural azaBINOLs. Drawing a parallel to an approach successfully used for the resolution of various BINOLs ${ }^{26}$ enantioenriched samples of 8,8'-diazaBINOL (3) were first obtained by chromatographic separation of the diastereomeric biscarbonates (43) formed by acylation with (+)-menthyl chloroformate (42), followed by saponification (Scheme 10). An XRD analysis of the biscarbonate antecedent [(-)-Ik-(aS)-43] of levorotatory 8,8'-diazaBINOL enabled unambiguous assignment of absolute configurations to the enantiomeric atropisomers of this parent azaBINOL as (-)-(aS)-3 and (+)-(aR)-3. ${ }^{3}$

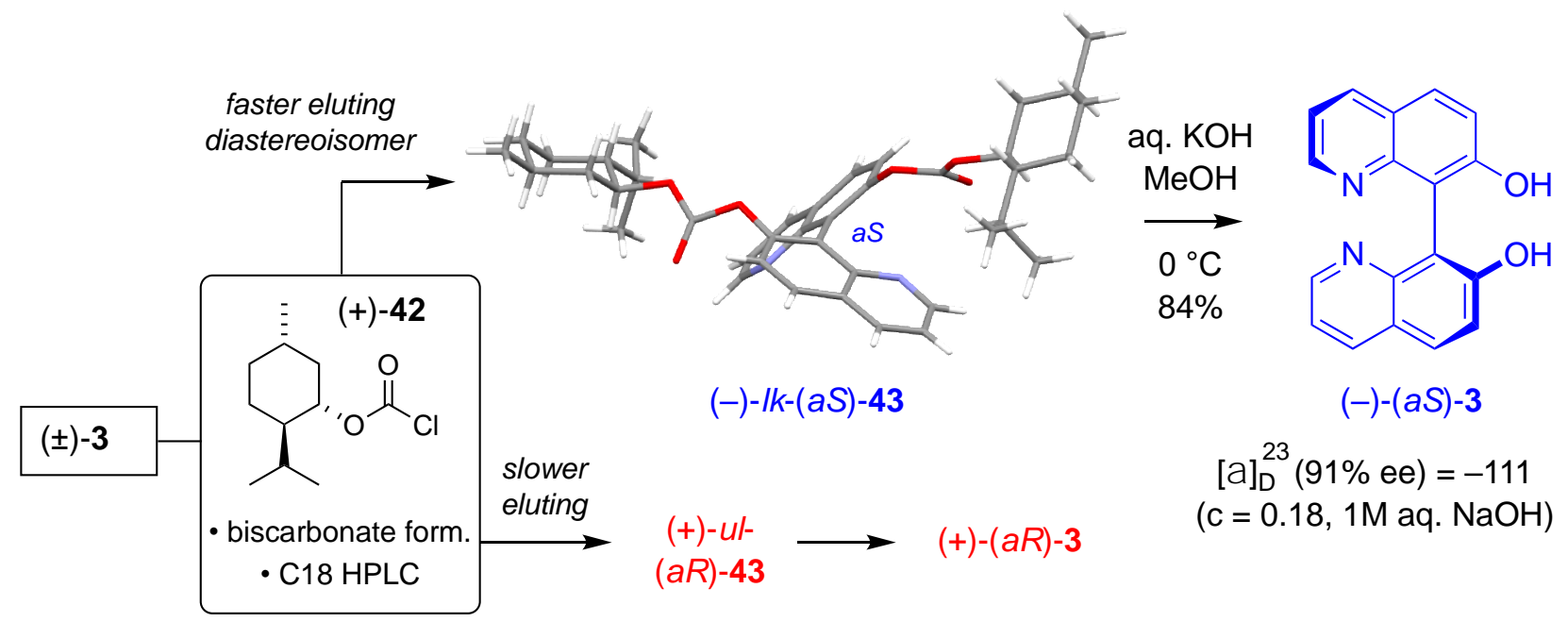

Scheme 10. Resolution of 8,8' -diazaBINOL (3) by chromatographic separation of diastereomeric bismenthyl carbonate derivatives (43) and assignment of absolute configuration as (-)-(aS)- $\mathbf{3}$ and (+)-(aR)- $\mathbf{3}$ by virtue of an XRD analysis of intermediate biscarbonate (-)-lk-(aS)-43. ${ }^{3}$

The biscarbonate resolution method was significant for providing absolute stereochemical assigments, but it is impractical to apply above a $500 \mathrm{mg}$ scale and so a superior method was sought to obtain scalemic azaBINOLs. Here again, the isostructural relationship between azaBINOLs and BINOL proved useful. Thus, Kazlauskas had reported the curious discovery that cholesterol esterase (a digestive enzyme found in mammalian pancreas) is an effective catalyst for the hydrolytic kinetic resolution of ( \pm )-BINOL diesters despite their lack of any obvious similarity with the natural substrate of the enzyme, cholesterol acetate. ${ }^{27}$ Adding to the utility of the method, it was found that the resolution does not require purified enzyme and that inexpensive bovine pancreas acetone powder (BPAP) will suffice. As anticipated, Kazlauskas' method proved highly effective for the resolution of the racemic dipentanoates of 8,8'-diazaBINOL (44) and 8-azaBINOL (45); also, and as for the dipentanoate of $( \pm)$-BINOL, it was found that (aS)-configured diesters of the azaBINOLs were hydrolyzed while their (aR)-antipodes were not (Scheme 11). ${ }^{4,9}$ 8,8'-DiazaBINOL (3) has limited configurational stability (see Section 3.2) and so it is best to immediately reconvert the product of esterase digestion, (-)-(aS)-3, back into (-)-(aS)-44, which has high configurational stability (e.g., no change in \%ee after $7 \mathrm{~d}$ at $110^{\circ} \mathrm{C}$ in toluene), for storage. When needed, scalemic samples of 3 are conveniently obtained by a mild and fast saponification procedure at $0{ }^{\circ} \mathrm{C} .{ }^{4}$ The heightened configurational stability of 8-azaBINOL (2) means that there is no need to store scalemic material in diester form; however, to safeguard against loss in \%ee over time, it should be kept in a refrigerator. ${ }^{9}$ 
<smiles>CCCCOC(=O)Oc1ccc2cccnc2c1-c1c(OC(=O)OCCC)ccc2cccnc12</smiles>

$( \pm)-44$

bovine pancreas acetone powder (BPAP) Na-taurocholate

$\mathrm{pH} 7.5$ buffer $\mathrm{Et}_{2} \mathrm{O}-\mathrm{H}_{2} \mathrm{O}, \mathrm{rt}, 62 \mathrm{~h}$

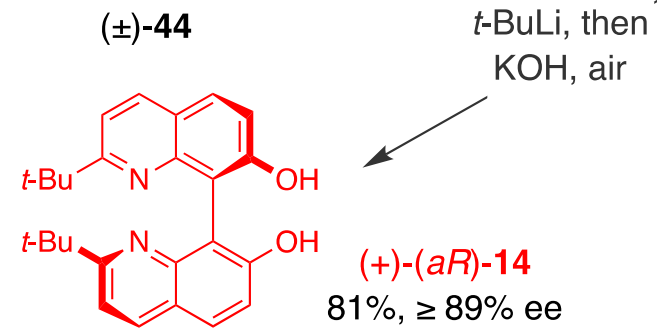

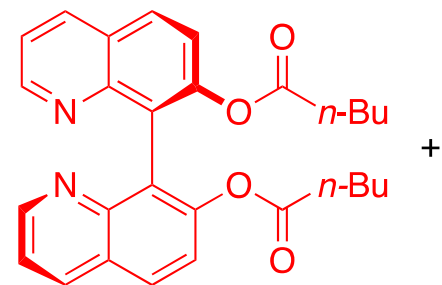

$(+)-(a R)-44$ $46 \%, \geq 99 \%$ ee

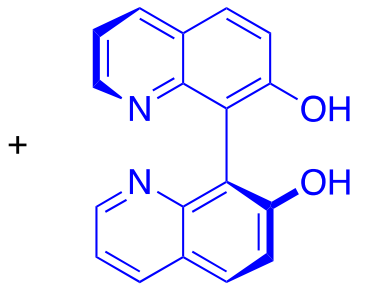

$(-)-(a S)-3$ $\geq 77 \%$ ee

\begin{tabular}{c|c} 
aq. $\mathrm{KOH}, \mathrm{MeOH}$ \\
$0{ }^{\circ} \mathrm{C}, 2 \mathrm{~h}$
\end{tabular} \mid $\begin{gathered}\text { re-esterify to } 44 \\
\text { then, recrystallize }\end{gathered}$
$(+)-(a R)-3$
$(-)-(a S)-44$
$83 \%, \geq 92 \%$ ee

substrate processed by BPAP<smiles>CCCCC(C)(C)Oc1ccc2cccnc2c1-c1c(OC(C)CC)ccc2ccccc12</smiles>

$( \pm)-45$

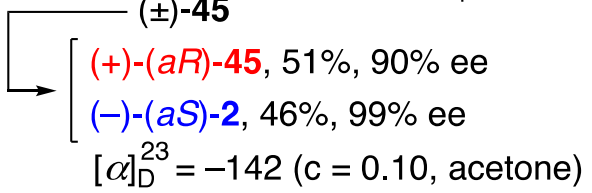

substrates not processed by BPAP<smiles>CCCCC(C)(C)Oc1ccc2ccc(C(C)(C)C)nc2c1-c1c(OC(C)(C)C)ccc2ccc(C(C)(C)C)nc12</smiles><smiles>[X]c1cc2cccnc2c(-c2c(OC(C)(C)C(C)(C)C)c([X])cc3cccnc23)c1OC(C)(C)C</smiles>

$( \pm)-47 a, X=I$

( \pm -47b, $X=\mathrm{SBn}$

( \pm )-47c, $\mathrm{X}=\mathrm{SO}_{2} \mathrm{~N}(\mathrm{Me})(\mathrm{CO} n-\mathrm{Bu})$

note: $47 c$ resolved by CSP HPLC

Scheme 11. Resolutions and attempted resolutions of azaBINOL diester derivatives using bovine pancreas acetone powder (BPAP). Resolution yields are given as the quotient of moles received to total moles of racemate input (i.e., $50 \%$ yield with $100 \%$ ee is a perfect resolution). ${ }^{4,9}$

Additional substituents, either at $\mathrm{C} 7 / \mathrm{C7}^{\prime}$ or $\mathrm{C3} / \mathrm{C3}^{\prime}$ on the azaBINOL scaffold, are not tolerated by the esterase; thus, neither $( \pm)-\mathbf{4 6}$ nor any of a family of potential precursors to bissulfonamide 5 [( \pm )-47abc] were processed by BPAP. The need to resolve $( \pm)-\mathbf{4 6}$ was obviated with the finding that addition of $t$-butyllithium to $(+)-(a R)-\mathbf{4 4}$ followed by oxidative saponfication of the intermediate double tert-butylated bisdihydroquinoline diester, gave the desired enantioenriched azaBINOL (+)-(aR)-14. ${ }^{4}$ Identification of a method to obtain bissulfonamide 5 in enantioenriched form was not easy and the prosaic solution ultimately identified to solve this problem, HPLC based separation of the atropisomers of tetrapentanoyl derivative ( \pm )-47c using a chiral stationary phase (CSP), ${ }^{7}$ belies the many alternative approaches that were investigated for this purpose. ${ }^{28}$ Of the unsuccessful resolution strategies that were evaluated, one of them gave a curious result that warrants comment here because it likely informs on the coordinating ability of azaBINOLs. Thus, it was anticipated that catalytic enantioselective sulfoxidation of racemic bissulfide $\mathbf{2 5}$ using the efficient method of Jackson et al. ${ }^{20}$ (as illustrated) would result in bifurcation of the starting material into a pair of enantioenriched bissulfoxide products, each of $C_{2}$-symmetry, one of 'like' relative configuration, $I k-C_{2}-(S, S, a S)-48$, and the other of 'unlike' relative configuration, $u l-C_{2}-(S, S, a R)-48$ (Scheme 12). The expectation here is of course that sulfoxide formation is reagent controlled and that the first oxidation event does not affect the second. In this scenario, the third possible diastereoisomer of 48, a non-symmetric pseudo-meso-type isomer, should not be formed. In 
the event, we were initially delighted when the experiment afforded two, and not three, diastereoisomers of 48, and each of those in an essentially equal quantity. The isomers were separable by standard silica gel column chromatography and the faster eluting one was discovered to possess $l k-C_{2}$-type stereochemistry by a single-crystal XRD analysis. However, conversion of the $I k-C_{2}-48$ so obtained to the biscarbamate precursor of bissulfonamide 5 (26) using the conditions shown in Scheme 5 (step b), gave optically inactive material. Furthermore, it was discovered that running the oxidation of $\mathbf{2 5}$ in the absence of a chiral ligand gave the same product diastereomer ratio. On the basis of the observed results, it is evident that sulfoxidation in this case is substrate-, and not reagent-, controlled; thus, it is not possible to escape the racemic starting state of $( \pm)-25$ with this particular implementation of the resolution concept envisioned. Nonetheless, it is likely that the general strategy embodied here could be effective for the resolution of racemic azaBINOLs using other types of enantioselective chemistry.<smiles>COc1c(Cc2ccccc2)cc2cccnc2c1-c1c(C(=O)Oc2ccccc2)c(SCc2ccccc2)cc2cccnc12</smiles>

$( \pm)-25, \mathrm{Cb}=\mathrm{CONEt}_{2}$
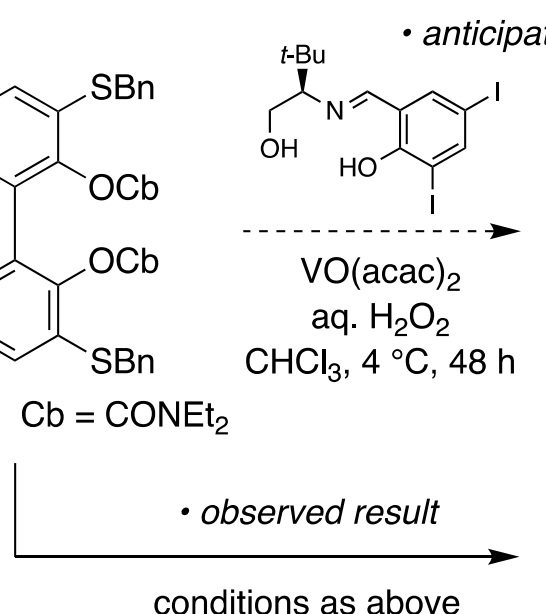

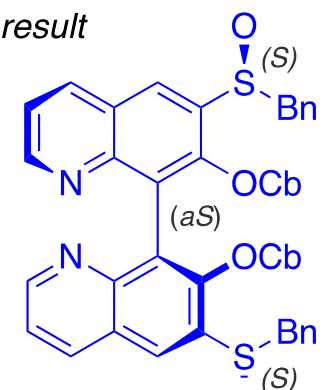

$\mathrm{O}^{-1}$<smiles>Oc1c(SCc2ccccc2)cc2cccnc2c1-c1c(OCc2ccccc2)c(S(O)(O)c2ccccc2)cc2cccnc12</smiles>

O(S)

ul- $C_{2}-(a R)-48$

Ik- $C_{2}-( \pm)-48,48 \%+$ unassigned diastereomer of $48,46 \%$

Scheme 12. An envisioned oxidative resolution of $\mathbf{2 5}$ by conversion of each atropisomer to a different diastereomer of $\mathbf{4 8}$ using an enantiopure chiral metal-complex (top) and the observed result (bottom). ${ }^{28}$

Perhaps as may be expected, BINOL and azaBINOL compounds share closely related chiroptical properties and they display the bisignate exciton Cotton effect features typical for biaryls in their electronic circular dichroism (eCD) spectra. ${ }^{30}$ For a given absolute configuration, the parent compounds 1, 2, and $\mathbf{3}$ share the same eCD exciton chirality phase with (aS)-isomers showing a positive exciton chirality phase (Figure 6)..$^{3,9}$ The exciton feature becomes weaker and it is red-shifted as the series is traversed from $\mathbf{1}$ to $\mathbf{2}$ to $\mathbf{3}$. In the absence of more definitive techniques to determine absolute configuration, exciton chirality phase may be used to make a tentative assignment of configuration for a given new scalemic azaBINOL derivative; however, it should be noted that biaryls of the same absolute configuration but with distinctly different preferred interannular dihedral angles (i.e., conformer distributions) need not share a common exciton chirality phase. ${ }^{30}$ 


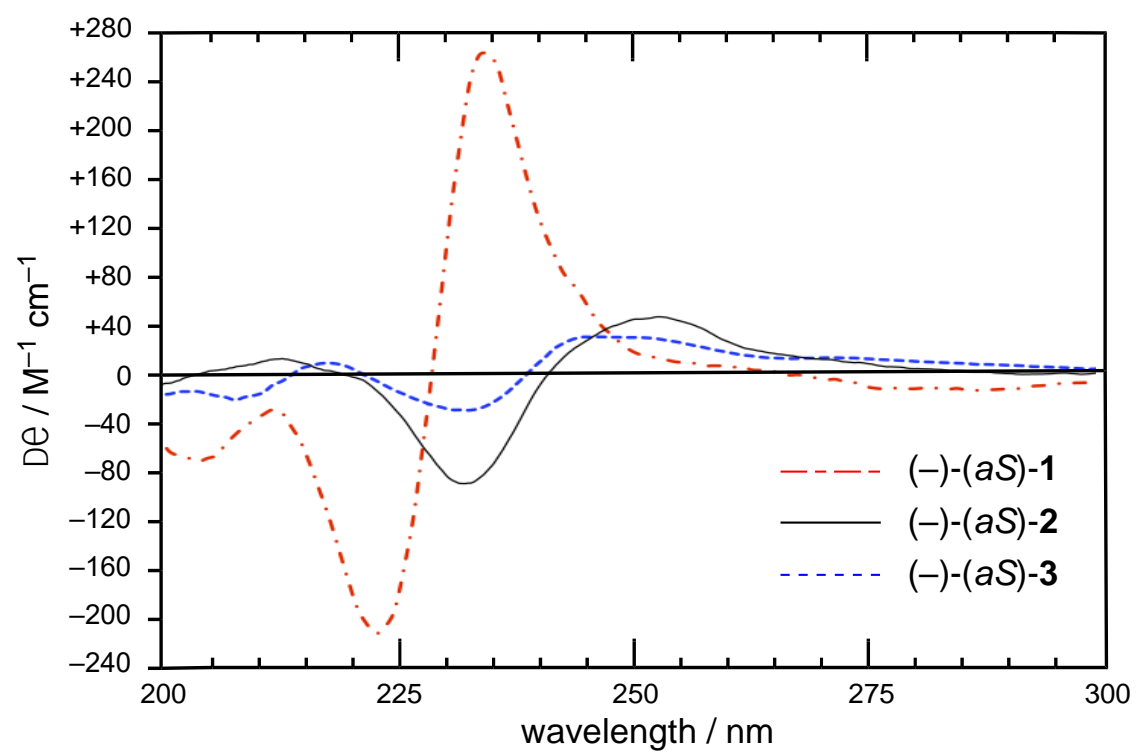

Figure 6. Electronic circular dichroism (eCD) spectra of levorotatory (aS)-configured azaBINOLs $(\mathbf{2}, \mathbf{3})$ and BINOL (1) each showing a positive exciton chirality phase. Spectra for (-)-(aS)-1 and (-)-(aS)-2 collected from $\mathrm{MeOH}$ solution and that for $(-)-(a S)-3$ from $\mathrm{H}_{2} \mathrm{O}$. All plots are corrected to $100 \%$ ee. ${ }^{3,9}$

\subsection{Enantiomerization and racemization kinetics of azaBINOLs}

Within this section, the enantiomerization and racemization behaviors of azaBINOL compounds and BINOL are considered. Some confusion exists in the literature as to the subtle distinction between the formal processes of racemization and enantiomerization, and so a brief digression will be taken here to define each of these 'reactions'. An excellent tutorial on this topic was recently provided by Mayor et al. ${ }^{31}$

- Racemization is a macroscopic process describing an ensemble of enantiomers attaining a net racemic state and it can be formalized for kinetic purposes as a first-order reaction involving a homochiral complex of a pair

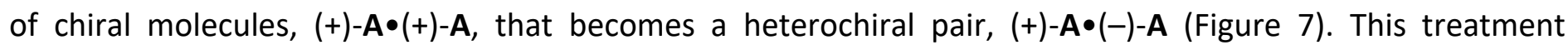
enables progression from an enantiopure (or enantioenriched) starting state toward a racemic final state to be mapped. As so defined, racemization has a conclusion and it is complete when all (+)-A molecules are equally paired with an (-)-A molecule partner such that there is no more free $(+)-\mathbf{A} \bullet(+)-\mathbf{A}$ 'starting material' (i.e., er $=$ 50:50). The rate of racemization is highest at the start of the reaction and it decays over time exponentially to become effectively zero after multiple half-lives of racemization have been endured.

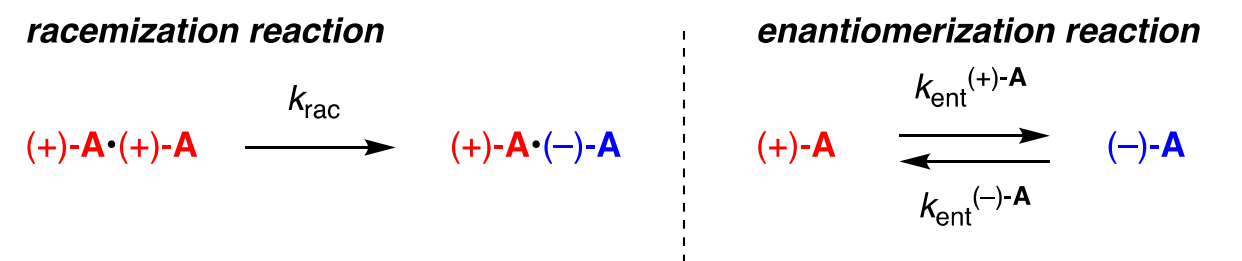

useful relations derived from rate laws

$$
k_{\text {rac }}=2 k_{\text {ent }} \quad \ln \left(\frac{\% e e_{0}}{\% e_{\mathrm{t}}}\right)=k_{\text {rac }} \mathrm{t}=2 k_{\text {ent }} \mathrm{t} \quad \tau_{1 / 2-\mathrm{rac}}=\frac{\ln 2}{k_{\mathrm{rac}}}=\frac{\ln 2}{2 k_{\text {ent }}}
$$

Figure 7. The formalized processes of racemization and enantiomerization and some useful relations derived from the rate laws for each. $\% e_{0}=\%$ ee at time $t=0 ; \%$ ee $=\%$ ee at time $t ; \tau_{1 / 2 \text {-rac }}=$ half-life of racemization. 
- Enantiomerization is a microscopic process describing the reaction of one molecule of $(+)-A$ becoming one molecule of (-)-A (Figure 7). In a spontaneous setting, this process cannot be separated from the reverse process, (-)-A to (+)-A, and the rate constants for forward and reverse reactions are necessarily equal $\left[k_{\text {ent }}{ }^{(+)-A}\right.$ $\left.=k_{\text {ent }}{ }^{(-)}\right]$. . By contrast to racemization, enantiomerization is a reaction without end that continues indefinitely. In the ensemble, forward and reverse reactions will have different rates at a non-racemic state, but over time the two rates will equalize as entropy is maximized en route to thermodynamic equilibrium and arrival at the racemate (i.e., er $=50: 50$ ).

Enantiomerization is a more natural and a less contrived process to consider than racemization; furthermore, the activation parameters of interest for probing mechanism of biaryl configurational inversion are necessarily those for the microscopic process of enantiomerization, $\Delta G^{\ddagger}{ }_{\text {ent }}, \Delta \mathrm{H}^{\ddagger}$ ent, and $\Delta \mathrm{S}_{\text {ent. }}^{\ddagger}{ }^{31}$ Nonetheless, arguably the most intuitively accessible metric regarding configurational stability for a given molecule is its racemization half-life at a given temperature; thus, it should be noted that the rate constant for racemization is equal to twice that of enantiomerization, $k_{r a c}=2 k_{\text {ent }}$, and so, $\tau_{1 / 2-\text { rac }}=(\ln 2) /\left(2 k_{\text {ent }}\right){ }^{31}$ Eyring plot analyses, which allow for extraction of the critical activation parameters, $\Delta \mathrm{H}^{\ddagger}{ }_{\text {ent }}$ and $\Delta \mathrm{S}^{\ddagger}$ ent, by measurement of the dependence of rate constants on temperature, ${ }^{32}$ were conducted for the enantiomerization reactions of parent azaBINOLs $(\mathbf{2}, \mathbf{3})$ and BINOL (1) ${ }^{3,9}$ Initial kinetic experiments concerning just 8,8'-diazaBINOL (3) were performed in water, ${ }^{3}$ and follow-up studies were later extended to all three compounds in DMSO, a mutually compatible solvent. ${ }^{9}$ A 2012 study by Davoren et al. provides additional data for BINOL (1) in diglyme. ${ }^{33}$ Data are collated together in Table 1 together with racemization half-lives obtained by substituting experimentally determined parameters $\Delta \mathrm{H}^{\ddagger}$ ent and $\Delta \mathrm{S}^{\ddagger}{ }_{\text {ent }}$ back into the Eyring equation at a given temperature of interest.

Table 1. Activation parameters for enantiomerization of parent azaBINOLs $(\mathbf{3}, \mathbf{2})$ and $\operatorname{BINOL}(\mathbf{1})$

\begin{tabular}{|c|c|c|c|c|c|}
\hline parameter / solvent & $\mathrm{H}_{2} \mathrm{O}^{3}$ & DMSO $^{9}$ & $\mathrm{DMSO}^{9}$ & $\mathrm{DMSO}^{9}$ & diglyme ${ }^{33}$ \\
\hline$\Delta \mathrm{H}_{\mathrm{ent}}^{\ddagger}\left(\mathrm{kcal} \mathrm{mol}{ }^{-1}\right)$ & +34.0 & +27.4 & +19.9 & +23.2 & +32.2 \\
\hline$\Delta \mathrm{S}_{\text {ent }}^{\ddagger}\left(\mathrm{cal} \mathrm{mol} \mathrm{m}^{-1} \mathrm{~K}^{-1}\right)$ & +18.7 & +3.8 & -27.9 & -25.3 & -15.6 \\
\hline temp. $\left({ }^{\circ} \mathrm{C}\right)$ & $\tau_{1 / 2 \text {-rac }}$ & $\tau_{1 / 2 \text {-rac }}$ & $\tau_{1 / 2 \text {-rac }}$ & $\tau_{1 / 2 \text {-rac }}$ & $\tau_{1 / 2 \text {-rac }}$ \\
\hline 25 & $1.2 \mathrm{y}$ & $12 \mathrm{~d}$ & $0.87 y$ & $62 y^{a}$ & $1.9 \times 10^{6} y$ \\
\hline 50 & $4.9 \mathrm{~d}$ & $7.2 \mathrm{~h}$ & $22 d$ & $2.8 y^{a}$ & $26 \times 10^{3} y$ \\
\hline 100 & $5.1 \mathrm{~min}$ & $73 \mathrm{~s}$ & $7.1 \mathrm{~h}$ & $6.8 d^{a}$ & $27 y$ \\
\hline 200 & $15 \mathrm{~ms}$ & $23 \mathrm{~ms}$ & $69 \mathrm{~s}$ & $10 \mathrm{~min}$ & $19 \mathrm{~h}$ \\
\hline
\end{tabular}

Activation parameters for enantiomerization of parent azaBINOLs $(\mathbf{3}, \mathbf{2})$ and BINOL $(\mathbf{1})$ as determined by Eyring plot analyses of kinetic experiments and calculated racemization half-lives $\left(\tau_{1 / 2-\text { rac }}\right)$ at given temperatures obtained from the Eyring equation using the experimentally determined values for $\Delta \mathrm{H}^{\ddagger}$ ent and $\Delta \mathrm{S}^{\ddagger}{ }_{\text {ent }}$. Eyring equation, $\left.\mathrm{k}=\left(\mathrm{k}_{\mathrm{B}} / \mathrm{h}\right) \cdot \mathrm{T} \cdot \exp \left[\left(-\Delta \mathrm{H}^{\ddagger}+\mathrm{T} \Delta \mathrm{S}^{\ddagger}\right) / \mathrm{RT}\right)\right]$. ${ }^{a}$ Indicated $\tau_{1 / 2-\text { rac }}$ values were erronenously listed as twice the illustrated magnitudes (i.e., $120 \mathrm{y}, 5.5 \mathrm{y}$, and $14 \mathrm{~d}$ ) in the original paper (ref. 9). ${ }^{3,9,33}$ 
Regarding the directly comparable data in common DMSO solvent, and as highlighted above, configurational stability within the series of three analogous biaryls conforms with the order $(\mathbf{1}>\mathbf{2}>\mathbf{3})$ expected based on simple heuristic grounds (Figure 5). However, the individual enantiomerization activation parameters for $\mathbf{3}$ are starkly different in their character to those for the naphthalene containing compounds $\mathbf{2}$ and 1. Thus, the factor responsible for the lower configurational stability of $\mathbf{3}$ is not a low $\Delta \mathrm{H}_{\text {ent }}^{\ddagger}$ value, which in fact is by far the highest within the series, but rather the finding that the entropy of activation for enantiomerization in this case is positive and not negative as for $\mathbf{2}$ and 1. . $^{3,9}$ One plausible explanation is that an ordered solvation sphere of solvent molecules in the ground state is disrupted on the journey to the transition state; in accord with such a hypothesis, both $\Delta \mathrm{H}^{\ddagger}$ ent and $\Delta \mathrm{S}^{\ddagger}$ ent values for $\mathbf{3}$ are heightened in water, where solvation effects would be much stronger than in DMSO (i.e., in the case of $\mathrm{H}_{2} \mathrm{O}$ and 3, both substrate and solvent are $\mathrm{H}$-bond donors and acceptors). The presence of a hydrophobic naphthyl unit in the chimeric azaBINOL 2 is perhaps enough to disrupt strong solvation effects and render it more akin to BINOL (1) than 8,8'-diazaBINOL (3), and, since 2 possesses only one and not two peri $\mathrm{CH}$ bonds, an attendant drop in $\Delta \mathrm{H}^{\ddagger}$ ent occurs that accounts for the lower configurational stability of $\mathbf{2}$ vs. 1. Before moving on, it is fascinating to note the enormous solvent dependence of enantiomerization rate for BINOL in DMSO vs. diglyme which at $25^{\circ} \mathrm{C}$ is ca. 30,000 times faster in the dipolar aprotic solvent as compared to the polyether.

Returning to the bond rotation view of enantiomerization (Figure 5), it is of interest which of the two simple pathways, syn or anti, is preferred for a given biaryl system to achieve its configurational inversion. In the case of BINOL (1), DFT calculations performed at the B3LYP/6-31G(d,p) level indicate that the anti-pathway (via an out-of-plane distorted structure similar to anti-41) is ca. $9 \mathrm{kcal} \mathrm{mol}^{-1}$ lower in energy than the comparable syn-pathway. ${ }^{34}$ We performed molecular mechanics calculations at the AM1 level for the enantiomerization of 8,8'-diazaBINOL (3) and located similarly bond distorted syn and anti transition structures but in this case the syn structure (syn-50) was found to be preferred by ca. $6 \mathrm{kcal} \mathrm{mol}^{-1}$ (Figure 7). ${ }^{3} \mathrm{~A}$ syn transition structure for the enantiomerization of $\mathbf{3}$ is expected to be particularly sensitive to low $(<2)$ or high (>12) pH extremes because its dicationic [2(+)-syn-49] or dianionic [2(-)-syn-51] forms encounter greater electrostatic destabilization than one would anticipate for the analogous anti transition structure. Lending some credence to the result of the calculation, it was found experimentally that $\mathbf{3}$ is indeed more configurationally stable at extremes of the $\mathrm{pH}$ scale as compared to $\mathrm{pH}$ 7. Thus, strongly alkaline $(1.0 \mathrm{M}$ aq. $\mathrm{NaOH})$ and strongly acidic $(1.0 \mathrm{M}$ aq. $\mathrm{HCl})$ solutions of optically active $\mathbf{3}$ showed no deterioration in \%ee during $20 \mathrm{~h}$ at $75^{\circ} \mathrm{C}$. The racemization half-life for 3 at the same temperature in neutral aqueous media is only ca. 2.5 h. Interestingly, and by contrast to 3 , BINOL (1) becomes less configurationally stable at pH extremes. ${ }^{35}$
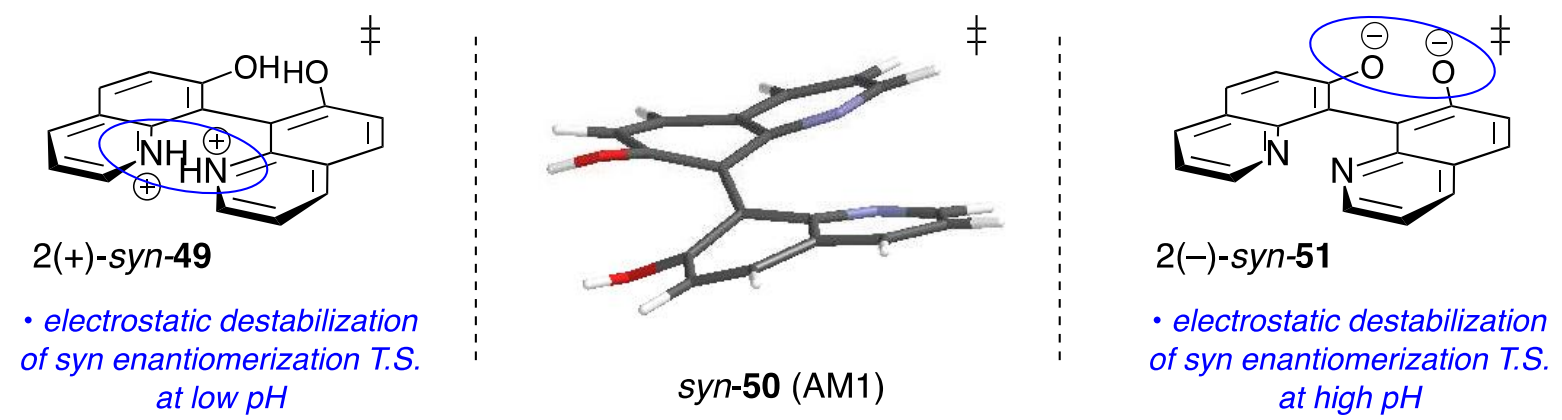

Figure 8. Lowest energy computed transition state for the enantiomerization of 8,8' -diazaBINOL (3) via AM1 molecular mechanics simulation and anticipated electrostatic destabilization of dicationic and dianionic forms. 
Significant solvent dependent trends for configurational stability have been observed for a number of more soluble azaBINOLs (Table 2). ${ }^{4,9}$ For example, 7,7'-di-tert-butyl-8,8'-diazaBINOL (14), a compound that is far less configurationally stable than 8,8'-diazaBINOL (3) despite possessing bulky substituents, racemizes 16 times faster in chloroform as compared to methanol. The solid-state (XRD analysis) structure of 14 exhibits interannular $\mathrm{H}$-bonds $(\mathrm{N} \cdots \mathrm{HO}$ ) between opposing quinol units (Figure 4) and disruption of these interactions, which presumably lower the barrier to configurational inversion, by a $\mathrm{H}$-bond donating/accepting solvent such as methanol, results in increased configurational stability. ${ }^{4}$ Consistent with this finding are the facts that 2deoxy-8-azaBINOL (52), which is also capable of supporting an interannular H-bond, is likewise less (33 times) configurationally stable in chloroform vs. methanol, while the racemization half-life for its regioisomer 2'deoxy-8-azaBINOL (53), which cannot form such a H-bond, does not show a strong solvent dependency. ${ }^{9}$ An unexpected exception to this behavior was observed for 8-azaBINOL (2) which, although embedding the same motif found within $\mathbf{5 2}$, actually exhibits greater configurational stability in chloroform than methanol. ${ }^{9}$

Table 2. Effect of solvent on racemization half-life for selection azaBINOL derivatives. ${ }^{4,9}$

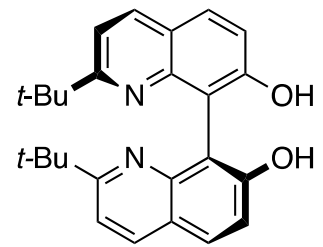

14

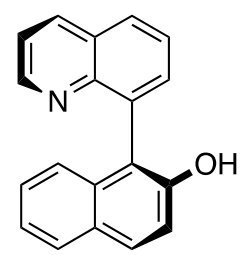

52

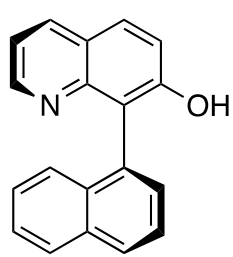

53

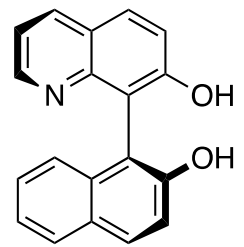

2

\begin{tabular}{ccccc} 
solvent & $\tau_{1 / 2 \text {-rac }}\left(23^{\circ} \mathrm{C}\right)$ & $\tau_{1 / 2 \text {-rac }}\left(24^{\circ} \mathrm{C}\right)$ & $\tau_{1 / 2 \text {-rac }}\left(24^{\circ} \mathrm{C}\right)$ & $\tau_{1 / 2 \text {-rac }}\left(56^{\circ} \mathrm{C}\right)$ \\
\hline $\mathrm{CHCl}_{3}$ & $1.9 \mathrm{~h}$ & $2.7 \mathrm{~h}$ & $106 \mathrm{~h}$ & $257 \mathrm{~h}$ \\
$\mathrm{MeOH}$ & $30.5 \mathrm{~h}$ & $89 \mathrm{~h}$ & $120 \mathrm{~h}$ & $70 \mathrm{~h}$ \\
\hline
\end{tabular}

Finally, it is noteworthy that two analogs of 8,8'-diazaBINOL (3) have been introduced by others that nicely retain the $\mathrm{C}_{2}$-symmetry and polyfunctionality inherent in the design of $\mathbf{3}$ while overcoming its poor solubility and modest configurational stability (Figure 9). ${ }^{36,37}$ Xiao and Loh prepared the bis(tetrahydroquinolyl) analog $\mathbf{5 4}$ by transfer hydrogenation of $\mathbf{1 3}$ followed by double $N$-methylation and saponification, and noted that the resolved enantiomers (obtained by chromatographic separation of diastereoisomeric menthyl carbonates, cf. Scheme 10) retained their enantiomeric excess for 'several months' upon storage at rt. ${ }^{36}$ Kitamura et al. increased configurational stability of the biquinoyl system of $\mathbf{3}$ by formally exchanging phenolic $\mathrm{OH}$ groups for bulkier hydroxymethyl moieties, as in 55. Interestingly, it was demonstrated that $\mathbf{5 5}$ can be accessed by analogy to the second generation synthesis of 8,8'-diazaBINOL (see Section 2.2) by a Pd(II)-mediated directed $\mathrm{CH}$ functionalization of $7,7^{\prime}$-dimethyl-8, $\mathbf{8}^{\prime}$-biquinol. ${ }^{37}$ Scalemic samples of $\mathbf{5 5}$, obtained by preparative chiral stationary phase HPLC based resolution of the racemate, or by application of the Pd(II) oxidation chemistry to enantioenriched 7,7'-dimethyl-8,8'-biquinol, exhibited no loss in optical activity after storage for two months at $r$ or after being refluxed in toluene solution. Applications for these potentially useful materials have yet to be reported. 


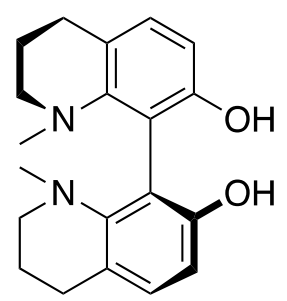

54

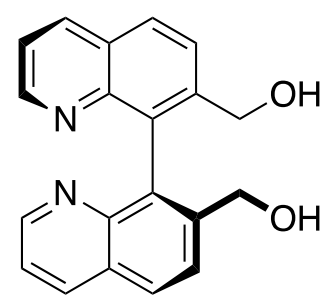

55

Figure 9. Two analogues of $8,8^{\prime}$-diazaBINOL (3) with heightened configurational stability and solubility. ${ }^{36,37}$

\section{Physical and Thermodynamic Properties of AzaBINOLs}

Some of the physical properties of azaBINOL compounds have been commented on above, for example, it is generally found that $8,8^{\prime}$-diazaBINOL derivatives are crystalline solids and the parent compound (3) is a high melting solid soluble only in dipolar and/or protic solvents (e.g., $\mathrm{H}_{2} \mathrm{O}$, DMSO, DMF). Masking of the phenolic $\mathrm{OH}$ groups as ethers or esters dramatically improves solubility, as does the addition of alkyl groups elsewhere (e.g., 14). By contrast to their symmetrical diaza counterparts, 8-azaBINOL derivatives of all kinds are generally soluble in common organic solvents but such compounds are less likely to be crystalline solids. The amphoteric nature of azaBINOLs is a key feature of these molecules and an attribute that may provide for applications in materials chemistry and reaction catalysis. The thermodynamic basicity of 8,8'-diazaBINOL ethers has been studied in detail and it is addressed within this section. ${ }^{5}$

\subsection{Dependence of basicity on conformation and response of interannular dihedral angle to $\mathrm{pH}$}

Polyfunctional biaryl compounds, like the azaBINOLs, provide a convenient platform for the study of proximity effects because opposing aromatic rings can be decorated with functional groups that must face one another across the biaryl axis. Interaction between the functional groups can be expected to modulate their reactivity and properties. In the case of $8,8^{\prime}$-diazaBINOL, in which weakly basic quinoline units are linked together by a single rotatable bond, we became intrigued by the possibility of inducing a 'proton sponge' type effect by forcing the quinolyl $\mathrm{N}$-atom lone-pairs into close proximity through the agency of a diether tether between the two phenolic $O$-atoms, as in $\mathbf{5 8}$ (Figure 10). Here, a dependency of $\mathrm{pK}_{\mathrm{aH}}$ (i.e., the $\mathrm{pK}_{\mathrm{a}}$ of the conjugate acid of the given base) on diether tether length was anticipated with an expectation that basicity would increase as $n$ is decreased. The original proton sponge, 1,8-bis(dimethylamino)naphthalene (56), was discovered by Alder to possess a remarkably high basicity $\left(\mathrm{pK}_{\mathrm{aH}}=12.3\right){ }^{38}$ some seven orders of magnitude higher than comparable simple anilines (i.e., $\mathrm{pK}_{\mathrm{aH}}$ of $\mathrm{N}, \mathrm{N}$-dimethylaniline is 5.2), because of the relief of lone-pair/lone-pair repulsion induced strain upon protonation. ${ }^{39}$ Heightened basicity due to the same kind of free base destabilization was found by Staab and coworkers for the benzannulated diquinoline $\mathbf{5 7}$, a compound topologically related to $8,8^{\prime}$ diazaBINOL, which is over five orders of magnitude more basic than quinoline $\left(\mathrm{pK}_{\mathrm{aH}} 4.9\right) .{ }^{40}$ Notwithstanding the structural resemblance of $\mathbf{5 8}$ (small $n$ ) to $\mathbf{5 7}$, it was found that the basicity of cyclic diethers $\mathbf{5 8}$ actually decreases significantly as $\mathrm{n}$ decreases. During the course of this work we also discovered that the interannular dihedral angle within diazaBINOLs is responsive to $\mathrm{pH}^{5}$ 
<smiles>CN(C)c1cccc2cccc(N(C)C)c12</smiles>

56

$\mathrm{pK}_{\mathrm{aH}}=12.3$

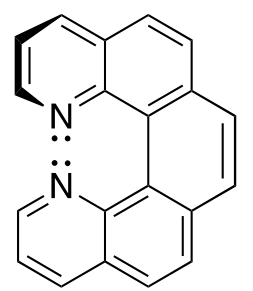

57

$\mathrm{pKaH}=10.3$

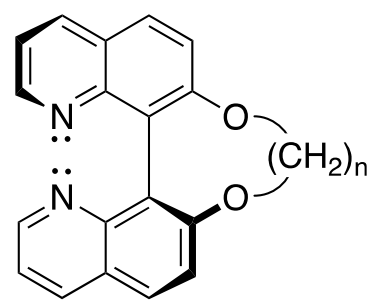

58

- dependence of $p K_{a H}$ on interannular dihedral angle? (modulated by $n$ )

Figure 10. Two compounds with strain induced heightened thermodynamic basicity, Alder's original proton sponge, 1,8-bis(dimethylamino)naphthalene (56), ${ }^{38}$ and Staab's diaza[5]helicene (57), ${ }^{40}$ and cyclic diether derivatives of 8,8'-diazaBINOL (58) with tunable interannular dihedral angles (IDA). ${ }^{5}$

Cyclic diethers 58 ( $n=1,3-6)$ were prepared in a straightforward manner from 8,8'-diazaBINOL (3) via the Williamson ether synthesis (Scheme 13). Attempts to access $58(n=2)$ using the same approach led instead only to the $\mathrm{N}, \mathrm{O}$-linked quinolinylquinolone $59 .^{5}$ All of the cyclic diethers were crystalline materials and each was subjected to XRD analysis, as was the dimethyl ether derivative of 8,8'-diazaBINOL (60) for comparative purposes (Figure 11; data for $n=4$ and 6 can be found in the original paper). ${ }^{5}$ The diether linkage fulfilled its desired function and interannular dihedral angle (IDA) was found to smoothly decrease as the alkylidene chain length was shortened; each cyclic diether was cisoid (i.e., acute IDA) while the non-constrained diether 60 exhibited a transoid (obtuse IDA) conformation. The observation of associated variations in $\lambda_{\max }$ for the ${ }^{1} \mathrm{~A} \rightarrow{ }^{1} \mathrm{~B}_{b}$ quinoline electronic transition, ${ }^{41}$ which has a long-axis aligned transition moment and so sensitive to IDA in 8,8'-diazaBINOLs, as the series of cyclic diethers 58 is traversed gave confidence that similar conformational changes are most likely also manifested in a solution phase. Acidity constants for the compounds of interest were determined by potentiometric titration in aqueous methanol. As noted above, the opposite trend to that expected for $\mathrm{pK}_{\mathrm{aH} 1}$ vs. $\mathrm{n}$ was observed, with the biquinolyls actually becoming less basic as IDA narrows and the $\mathrm{N}$-atom/N-atom contact distance lessens, to the extent that $\mathbf{5 8}(n=1)$ is over two orders of magnitude less basic than its unconstrained congener $\mathbf{6 0}$. It is likely that the biquinolyl lone-pairs within $58(n=1)$ remain too far apart for strain-induced basicity effects to operate. Instead, as IDA tightens, the ease of solvation of the biquinolinium monocationic conjugate acid form is presumably lessened due to steric effects and so there is an attenuation in basicity (solvation effects are well appreciated to be an important factor in determining $\mathrm{pK}_{\mathrm{aH}}$ for alkylamines). ${ }^{42}$

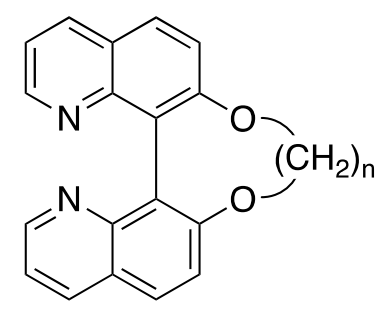

58

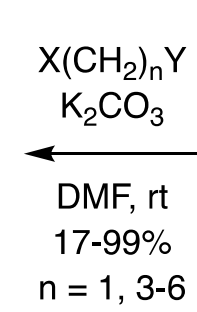

$n=1,3-6$

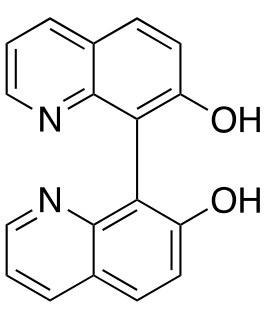

3

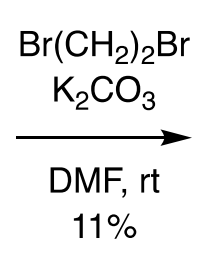

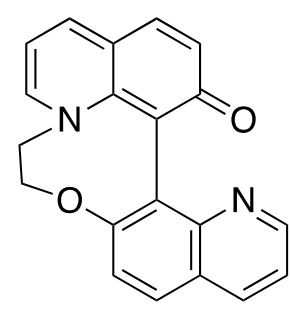

59

Scheme 13. Synthesis of cyclic diethers $58(n=1,3-6)$ and unexpected generation of quinolylquinolone $59 . X$, $\mathrm{Y}=\mathrm{Cl}, \mathrm{Br}$, or I. ${ }^{5}$ 


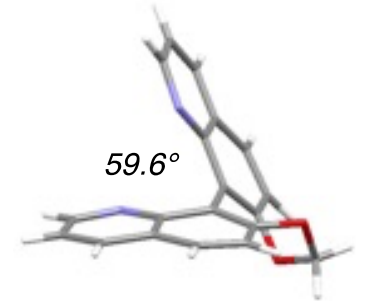

$$
\begin{aligned}
\mathbf{5 8}(\mathrm{n}=1) \\
\mathrm{N} \ldots \mathrm{N}=3.04 \AA \\
\lambda_{\max }\left({ }^{1} \mathrm{~B}_{\mathrm{b}}\right)=233 \mathrm{~nm} \\
\mathrm{pK}_{\mathrm{aH} 1}=3.1 \pm 0.5 \\
\mathrm{pK}_{\mathrm{aH} 2}=\text { not found }
\end{aligned}
$$

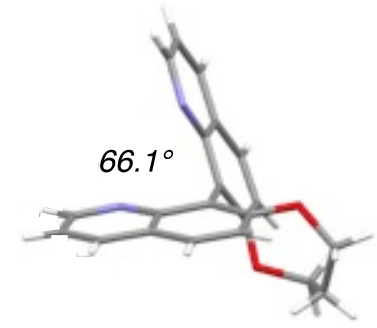

$58(n=3)$

$N$...N $=3.16 \AA$

$\lambda_{\max }\left({ }^{1} \mathrm{~B}_{\mathrm{b}}\right)=239 \mathrm{~nm}$

$\mathrm{pK}_{\mathrm{aH} 1}=4.69 \pm 0.11$

$\mathrm{pK}_{\mathrm{aH} 2}=2.64 \pm 0.08$

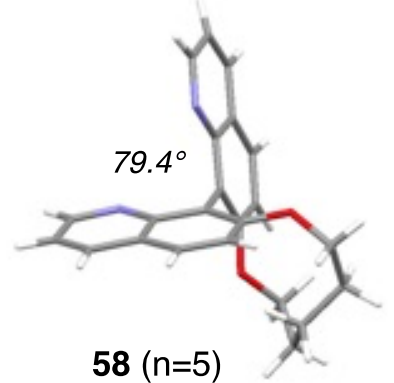

$58(\mathrm{n}=5)$

$$
\begin{aligned}
\mathrm{N} . . \mathrm{N} & =3.38 \AA \\
\lambda_{\max }\left({ }^{1} \mathrm{~B}_{\mathrm{b}}\right) & =240 \mathrm{~nm} \\
\mathrm{pK}_{\mathrm{aH} 1} & =5.15 \pm 0.01 \\
\mathrm{pK}_{\mathrm{aH} 2} & =2.63 \pm 0.30
\end{aligned}
$$

60

$$
\begin{aligned}
\mathrm{N} . . \mathrm{N} & =4.24 \AA \\
\lambda_{\max }\left({ }^{1} \mathrm{~B}_{\mathrm{b}}\right) & =238 \mathrm{~nm} \\
\mathrm{pK}_{\mathrm{aH} 1} & =5.21 \pm 0.38 \\
\mathrm{pK}_{\mathrm{aH} 2} & =2.69 \pm 0.36
\end{aligned}
$$

Figure 11. Solid state structures for cyclic diethers $\mathbf{5 8}(n=1,3,5)$ and dimethyl ether $\mathbf{6 0}$ obtained from single crystal X-ray diffraction analyses, structural and spectroscopic parameters of interest, and acidity constants determined by potentiometric titration experiments in $\mathrm{MeOH} / \mathrm{H}_{2} \mathrm{O}{ }^{5}$

A corollary to the fact that basicity of $8,8^{\prime}$-diazaBINOLs is dependent on IDA was established with the finding that the preferred IDA of unconstrained examples is influenced by their protonation state. Thus, in the solid state (XRD analyses, see Figure 12), the IDA for dimethyl ether $\mathbf{6 0}$ was found to transition from obtuse to acute upon monoprotonation with perchloric acid $\left(60\right.$ to $\left.60 \bullet \mathrm{HClO}_{4}\right)$ and then to return to an obtuse state upon addition of a second proton $\left(60 \bullet \mathrm{HClO}_{4}\right.$ to $\left.60 \cdot 2 \mathrm{HClO}_{4}\right)$. The cisoid nature of $60 \bullet \mathrm{HClO}_{4}$ was attributed to Coulombic attraction between the cationic quinolinium ring and the opposing electron-rich/basic quinoline ring that still possesses its $\mathrm{N}$-atom lone-pair. By contrast, electrostatic repulsion between the cationic sites within $60 \cdot 2 \mathrm{HClO}_{4}$ may account for its transoid conformation. Lending some credence to this argument, it was found that $58(n=1)$ could not be converted beyond its monoprotonated state $\left[58 \bullet \mathrm{HClO}_{4}(n=1)\right]$ to the putative double salt $\mathbf{5 8} \cdot 2 \mathrm{HClO}_{4}(n=1)$. In this case, repulsion within such a dication cannot be relieved by a widening in IDA because the short cyclic diether tether does not allow for such conformational flexibility (note: the solid state IDA for $\mathbf{5 8} \bullet \mathrm{HClO}_{4}(n=1)$ was found to lie between $50.8-53.6^{\circ}$ by XRD analysis). ${ }^{5}$

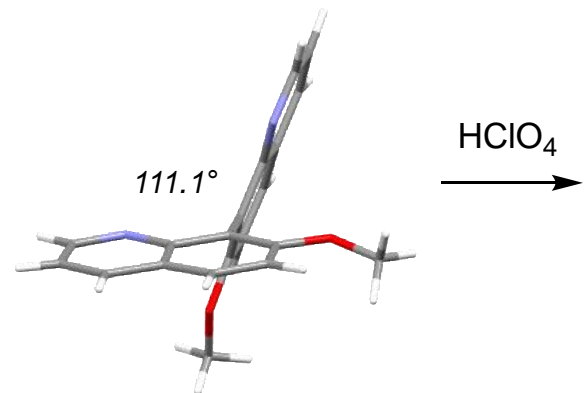

60

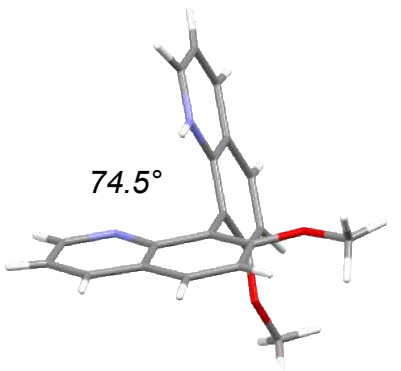

$60 \cdot \mathrm{HClO}_{4}$

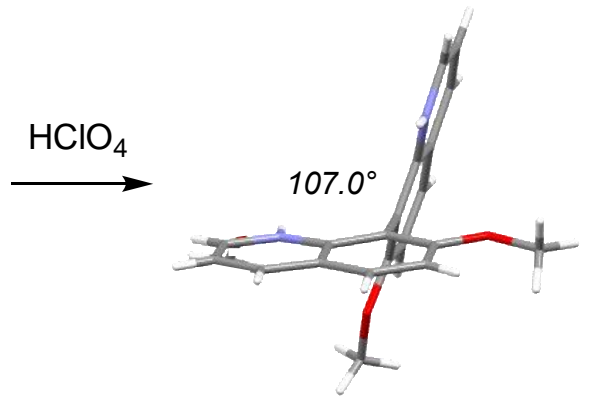

$60 \cdot 2 \mathrm{HClO}_{4}$

Figure 12. Solid state structures for dimethyl ether 60 and its single $\left(60 \bullet \mathrm{HClO}_{4}\right)$ and double perchlorate salts $\left(60 \cdot 2 \mathrm{HClO}_{4}\right)$ obtained from single crystal X-ray diffraction analyses. Perchlorate counter anions and solvent molecules are omitted for clarity. ${ }^{5}$ 


\section{Promotion and Stereocontrol of Reaction Chemistry by AzaBINOLs}

The polyfunctional nature of azaBINOLs, the ease with which such structures can be decorated with additional ancilliary moieties, and their inherent axially chirality, offer numerous opportunities for utilization of these biaryl molecules as catalysts, reagents, and/or metal ligands in enantioselective synthesis. Of primary interest are reaction types that may benefit specifically from the presence of the quinoline $\mathrm{N}$-atoms and that could not necessarily be replicated by simpler carbocyclic BINOL-based compounds. Documented in this section are our explorations of various azaBINOL derivatives as reaction promoters and stereocontrolling elements in a range of processes of contemporary interest.

\subsection{Silylcyanation of $C=X$ bonds catalyzed by a bissulfonamidyl $8,8^{\prime}$-diazaBINOL derivative}

As related above (Section 1.1), the original motivation for studying azaBINOLs was to realize an ambifunctional catalyst of type 4, conceivably embodied by a notional metal complex (6) of sulfonamide 5 . Silylcyanation of carbonyl compounds and imines was selected as a suitable benchmark process to explore the effectiveness, or otherwise, of such a construct since it is known that the addition of TMSCN across C=X bonds benefits from dual activation of the pro-nucleophile and the electrophile. ${ }^{43}$ Shibasaki's complex $\mathbf{7}$ and Najera's complex $\mathbf{8}$ are examples of BINOL-based ambifunctional silylcyanation catalysts that were known at the time of our work to promote highly enantioselective cyanohydrin formation; ${ }^{12,13}$ however, the orientation of Lewis acid and Lewis basic sites in each of them is fundamentally different from that envisioned in $\mathbf{6}$. Unfortunately, experiments to elucidate the speciation of metal ions by bissulfonamide $\mathbf{5}$ following its incubation with various metal sources (e.g., $\mathrm{BH}_{3} \bullet$ thf, $\mathrm{MeB}(\mathrm{OH})_{2}, \mathrm{Me}_{2} \mathrm{AlCl}$ ) were inconclusive; ${ }^{28}$ nonetheless, we moved forward with an examination of TMSCN addition to benzaldehyde with and without $\mathrm{AI}(\mathrm{III})$ and $\mathrm{Ti}(\mathrm{IV})$ metal additives and in the presence or absence of BINOL (1), 8,8'-diazaBINOL (3), and bissulfonamide 5 (Scheme 14). ${ }^{7}$

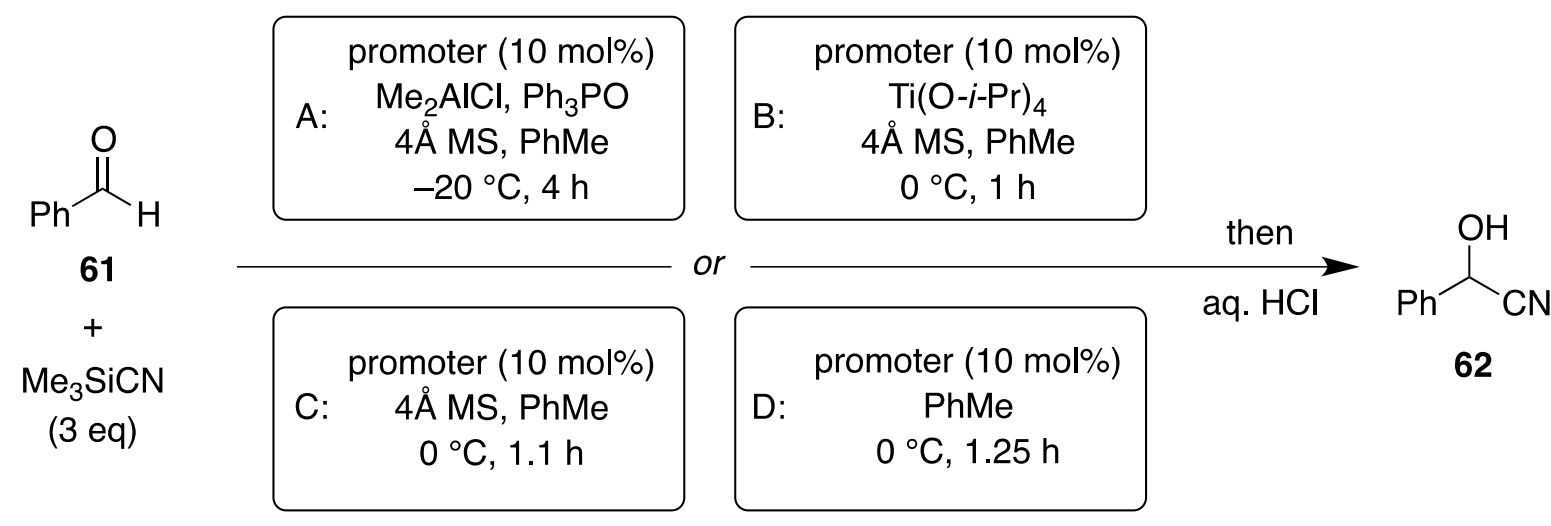

\begin{tabular}{ccccc} 
promoter & none & BINOL (1) & $\begin{array}{r}8,8^{\prime} \text {-diaza } \\
\text { BINOL (3) }\end{array}$ & $\begin{array}{c}\text { bissulfon- } \\
\text { amide 5 }\end{array}$ \\
\hline conditions: & A: $28 \%$ & A: $15 \%$ & A: $15 \%$ & A: $82 \%$ \\
$\%$ conversion & B: $28 \%$ & B: $9 \%$ & B: $44 \%$ & B: $\geq 98 \%$ \\
of 61 to 62 & C: $19 \%$ & C: $25 \%$ & C: $33 \%$ & C: $\geq 98 \%$ \\
& D: $0 \%$ & D: $0 \%$ & D: $0 \%$ & D: $\geq 98 \%$
\end{tabular}

Scheme 14. Silylcyanation of benzaldehyde with and without metal additives in the presence or absence of BINOL (1), 8,8' -diazaBINOL (3), and bissulfonamide 8,8' -diazaBINOL derivative $\mathbf{5}^{7}$

The surprising outcome of this study was the finding that bissulfonamide $\mathbf{5}$ itself, in the absence of any other components save for TMSCN and the aldehyde (Conditions D), was uniquely effective in promoting 
formation of the cyanohydrin, essentially as an organocatalyst. The silylcyanation reaction was extended to other aldehydes [RCHO: e.g., $\mathrm{R}$ (\%yield) $=\mathrm{BnCH}_{2}$ (89\%), $c-\mathrm{C}_{6} \mathrm{H}_{11}(86 \%),(E)-\mathrm{PhCH}=\mathrm{CH}(90 \%), 1-$ naphthyl (92\%), 3pyridyl (42\%)] and a limited number of ketones [RCOMe: $\mathrm{R}$ (\%yield) $=\mathrm{Ph}(22 \%), n-\mathrm{C}_{6} \mathrm{H}_{13}(82 \%)$ ] and aldimines $\left(\mathrm{RCH}=\mathrm{NBn}: \mathrm{R}\right.$ (\% yield) = 3- $\mathrm{ClC}_{6} \mathrm{H}_{4}(72 \%), 3-$ pyridyl (14\%)]. ${ }^{7}$ Although it is a highly effective chemical promoter of silylcyanation, when bissulfonamide $\mathbf{5}$ was re-evaluated in scalemic form (>80\% ee) it was revealed to be an inefficient stereoinductive element and cyanohydrin products were generated from aldehydes with uniformly low enantioselectivities [<10\% ee, $(-)-(a R)-5$ gives cyanohydrins with $(S)$-configuration]. ${ }^{7}$

To identify which structural features are responsible for the organocatalytic activity of $\mathbf{5}$, a series of related sulfonamides were prepared and likewise evaluated as promoters for the conversion of benzaldehyde (61) to mandelonitrile (62) (Figure 13). Aside from additional methylation of the sulfonamidyl NHMe group (63), all other structural changes investigated significantly lowered catalytic activity or eliminated it altogether. Thus, loss of free phenolic $\mathrm{OH}$ groups (26 and 66) or quinoline $\mathrm{N}$-atoms (65) resulted in catalytically incompetent molecules while a monomeric quinoline analog of 5 (64) was barely active, revealing that the proximity of contrasting functional groups on opposite sides of the biaryl axis is important for effective silylcyanation. ${ }^{7}$

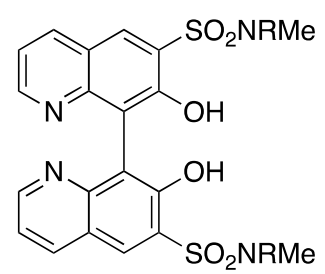

$\mathrm{R}=\mathrm{H}: \mathbf{5}(\geq 98 \%)$ $R=$ Me: $63(\geq 98 \%)$

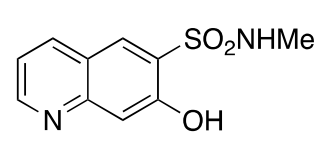

$64(2 \%)$

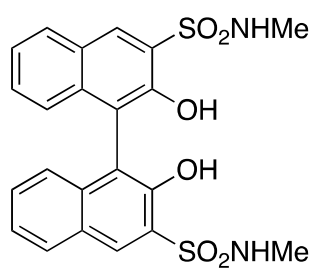

$65(0 \%)$

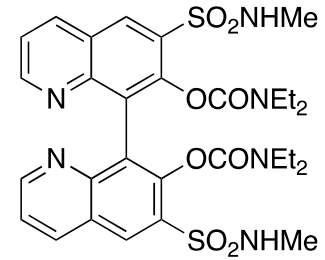

$26(0 \%)$

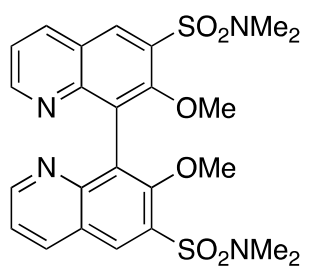

$66(0 \%)$

Figure 13. Evaluation of sulfonamides related to $\mathbf{5}$ as organocatalysts for the addition of TMSCN to PhCHO (61). Numbers in parentheses are the conversion of $\mathbf{6 1}$ to 62 using the indicated promoter and reaction conditions D (as shown in Scheme 14).

The above findings suggest that bissulfonamide $\mathbf{5}$ exerts its catalytic action through a combination of $\mathrm{H}$ bond /Brønsted acid effects ${ }^{44}$ (need for phenolic $\mathrm{OH}$ groups with vinylogous sulfamic acid character) aided by a general base capability (need for quinoline $\mathrm{N}$-atoms) with close proximity (need for biaryl). On the basis of this analysis, and conforming to validated models proposed for other organocatalytic platforms for silylcyanation, ${ }^{45}$ the mode of action of $\mathbf{5}$ is proposed to involve initial silylation of an acidic phenol by TMSCN then transfer of the resulting biquinolyl associated $\mathrm{HCN}$ to the aldehyde, itself activated by $\mathrm{H}$-bond donation from an $\mathrm{NH}$ or $\mathrm{OH}$ moiety (Scheme 15$).{ }^{7}$ Consistent with a process that benefits from a bifunctional catalyst but with a rate-determining step requiring electrophilic activation of the aldehyde, ${ }^{46}$ a modestly positive reaction constant $(\rho=+1.52)$ was measured by a Hammett analysis of silylcyanation of a series of 4 substituted benzaldehydes. ${ }^{7}$ The low enantioselectivity realized by this chemically efficient mode of organocatalysis is not surprising when given the expectation of weakly directional interactions within the putative transition state assembly 67 and the fairly open space occupied by the aldehyde substrate. Conceivably, structural variations to bissulfonamide $\mathbf{5}$ could result in a more enantioselective catalyst. 


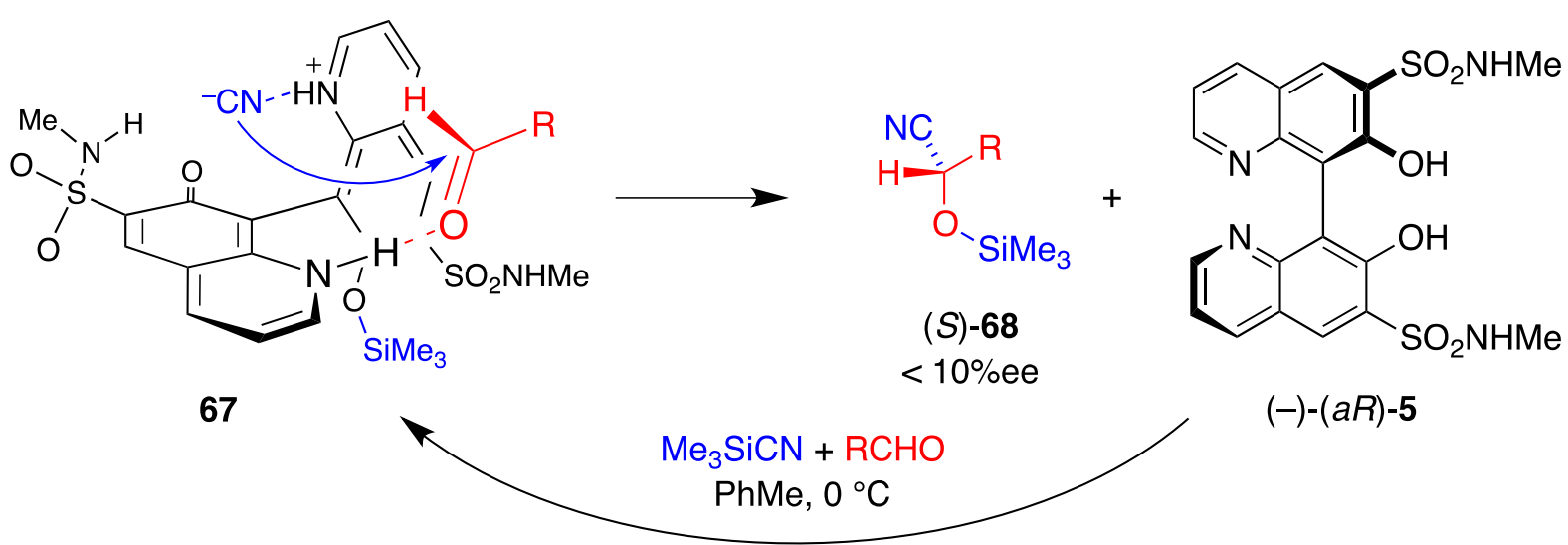

Scheme 15. A mechanistic proposal and stereocontrol model for the addition of TMSCN to aldehydes as catalyzed by bissulfonamide 5. $^{7}$

\subsection{Enantioselective Suzuki-Miyaura reactions mediated by a phosphanyl $8,8^{\prime}$-diazaBINOL derivative}

Axially chiral molecules, such as BINOL (1), ${ }^{1}$ its related bisphosphine analog BINAP (69), ${ }^{47}$ and the isoquinolyl substituted naphthalene biaryl system QUINAP (70), ${ }^{48}$ are most commonly applied as chiral ligands to enable enantioselective metal-catalyzed processes (Figure 14). An obvious question to ask is whether members of the azaBINOL family could be similarly useful as simple ligands in metal-based asymmetric catalysis? The presence of multiple hard (phenoxide) and soft (quinoline $\mathrm{N}$-atoms, arene) coordination sites within 8,8' -diazaBINOL (3) complicates how a given metal center may be ligated; thus, for initial work, we elected to study a somewhat less complicated azaBINOL derived system, monophosphine $\mathbf{7 2} .^{8}$ Phosphine $\mathbf{7 2}$ is a nitrogenous analog of the well-studied monophosphine ligand MOP $(\mathbf{7 1})^{49}$ with the possibility of engaging a metal through interactions with both $\mathrm{N}$ - and $\mathrm{P}$-atoms but in a manner quite distinct to the N/P ligand QUINAP (70).<smiles>Pc1ccc2ccccc2c1-c1c(P)ccc2ccccc12</smiles>

$(a R)$-BINAP (69)<smiles></smiles>

(aR)-QUINAP (70)<smiles>COc1ccc2ccccc2c1-c1c(P)ccc2ccccc12</smiles>

(aR)-MOP (71)<smiles>CCCCOc1ccc2cccnc2c1-c1c(P)ccc2cccnc12</smiles>

(aR)-72

Figure 14. Three well-known axially chiral biaryl phosphine ligands (69-71) and an 8,8'-diazaBINOL analog of MOP (72).

Phosphanylbiquinolyl 72 was accessed in a scalemic form from racemic 8,8'-diazaBINOL (3) via Pd-catalyzed nucleophilic substitution of triflate $\mathbf{7 3}$ with diphenylphosphine in the presence of air, followed by resolution of the resulting phosphine oxide (74) by chiral stationary phase (CSP) HPLC and then reduction (Scheme 16). The absolute configuration of the enantiomeric atropisomers of $\mathbf{7 4}$ were assigned by comparison of eCD spectra with that obtained from the phosphine oxide derivative of (aR)-MOP. Phosphine $\mathbf{7 2}$ is configurationally stable beyond $100{ }^{\circ} \mathrm{C}$ in toluene, but it is chemically labile toward oxidative conversion back to its phosphine oxide $\mathbf{7 4}$ in solution in the presence of air (and indeed, much more so than MOP). ${ }^{8}$ 


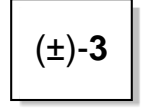

(a) n-BuOH, $\mathrm{Ph}_{3} \mathrm{P}, \mathrm{DEAD}$ THF, rt, $4 \mathrm{~h}, 76 \%$

(b) $\mathrm{Tf}_{2} \mathrm{O}$, pyridine, $\mathrm{rt}$ $71 \mathrm{~h}, 93 \%$

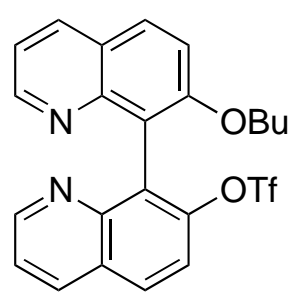

$( \pm)-73$ (a) $\mathrm{Pd}_{2} \mathrm{dba}_{3}, \mathrm{dppf}$

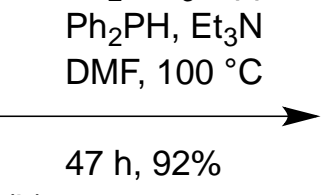

(b) CSP HPLC resolution

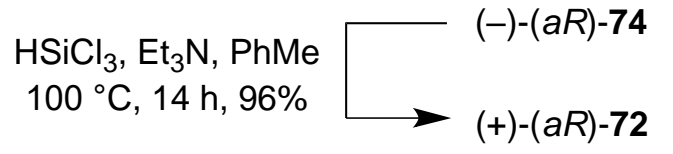

Scheme 16. Synthesis of phosphine ligand 72 from 8, $8^{\prime}$-diazaBINOL (3). ${ }^{8}$

The efficacy of (ar)-72 as a stereocontrolling chiral ligand for metal catalyzed enantioselective synthesis was evaluated in the context of the Suzuki-Miyaura cross-coupling approach to axially chiral biaryl molecules ${ }^{50}$ and results were compared to its carbocyclic ligand congener (ar)-MOP (71) (Scheme 17). ${ }^{8}$ AzaBINOL phosphine $\mathbf{7 2}$ was found to be more efficient than MOP for the generation of modestly hindered biaryls $(\mathbf{7 7 a}, \mathbf{b})$ but it was inferior in terms of both yield and enantioselectivity for the preparation of tetra-orthosubstituted biaryls $(\mathbf{7 7 c}, \mathbf{d})$. Significantly, that 8,8'-diazaBINOL derivative $\mathbf{7 2}$ is not simply an isostere for MOP (71) was revealed by the fact that the (ar)-enantiomer of each of these ligands produced hindered biaryls (77c and 77d) with the opposite absolute configuration. Also of note, the excellent stereoselectivity provided by the commercially available MOP ligand for enantioselective Suzuki-Miyaura reactions was unknown prior to this study. ${ }^{8}$

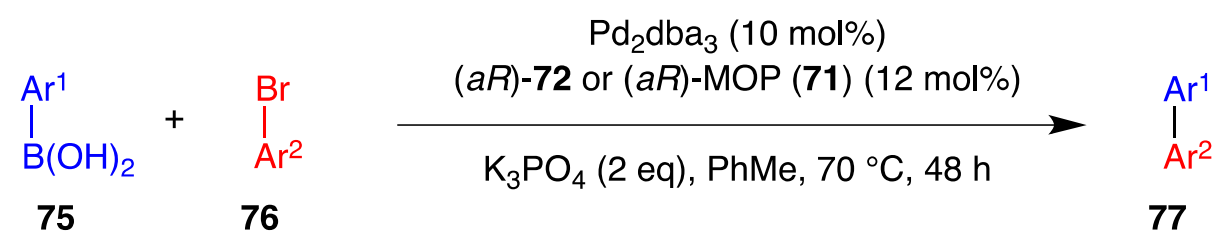

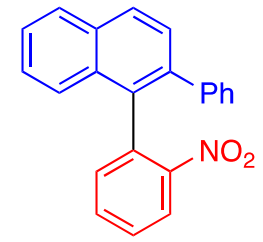

$77 a$

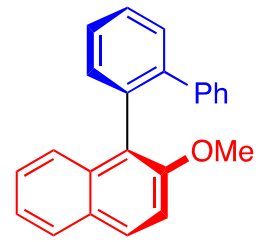

(+)-(aS)-77b

$97 \%,+20 \%$ ee

nd<smiles></smiles>

77c

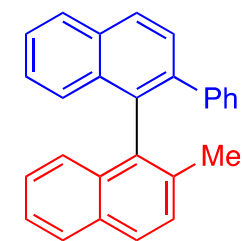

77d

$$
\text { with }(a R)-72: \quad 94 \%,-50 \% \text { ee }
$$

(aR)-MOP (71): $\quad 76 \%,-54 \%$ ee

Scheme 17. Enantioselective formation of biaryls by Suzuki-Miyaura cross-coupling catalyzed by $\operatorname{Pd}(0)$ complexes of biquinolyl phosphine (aR)-72 or (aR)-MOP (71). The sign associated with a given ee value is the sign of the optical rotation value for the biaryl product 77 obtained. ${ }^{8}$

\subsection{Miscellaneous processes mediated by azaBINOL derivatives}

Two applications of azaBINOL derivatives that have been explored in a more preliminary fashion are presented in this section: phase-transfer catalysis (PTC) using biquinolinium salts and direct amidation using an azaBINOL derived boronic acid. ${ }^{28,51}$ Although in each case only limited success was realized, new chemotypes that can be 
accessed from the basic $8,8^{\prime}$-diazaBINOL scaffold are revealed and it is hoped that the disclosure of this data here will provide a stimulus for further azaBINOL research.

5.3.1. Phase transfer catalysis with biquinolinium cations derived from $\mathbf{8 , 8} \mathbf{8}^{\prime}$-diazaBINOL diethers. Enantioselective PTC using chiral organocations is a powerful means to effect a wide variety of reactions. ${ }^{52}$ O'Donnell and co-workers described the first genuinely useful such method; a synthesis of $\alpha$-amino acids via alkylation of glycinate imine $\mathbf{8 1}$ in a two-phase solvent system promoted by quaternized ammonium salts prepared from cinchona alkaloids. ${ }^{53}$ There are obvious limitations on the kind of organocationic structural motifs that can be accessed from alkaloid based templates and so, in a departure from tradition, Maruoka et al. introduced a novel class of organocations for enantioselective PTC based on axially chiral spiroammonium salts. ${ }^{54}$ Further new types of chiral cations for PTC have been introduced more recently, including quaternary phosphonium salts derived from BINAP. ${ }^{55}$ A vast majority of known chiral PTC's contain sp ${ }^{3}$-hybridized cationic atoms (N or P) and although achiral pyridinium cations have been previously employed in PTC applications, ${ }^{56}$ extensions to chiral analogs have not been reported. To explore the possibility of enantioselective PTC based on non-sp ${ }^{3}$ hybridized cationic centers, a small collection of biquinolinium salts 79 were prepared from $8,8^{\prime}$-diazaBINOL diesters 78 and evaluated in the O'Donnell reaction (Scheme 18). ${ }^{51}$
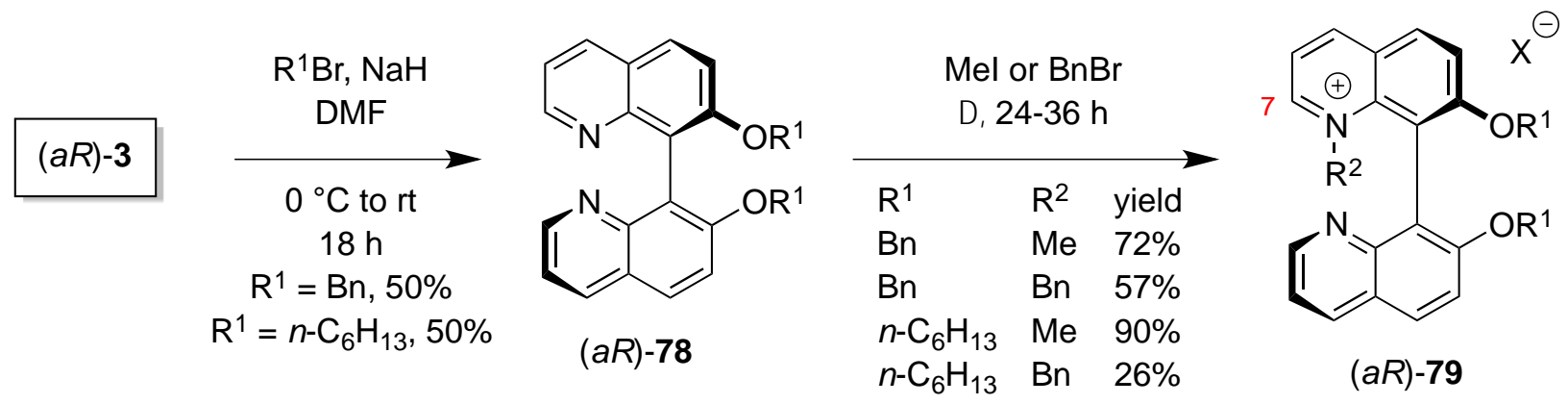

$(a R)-79$

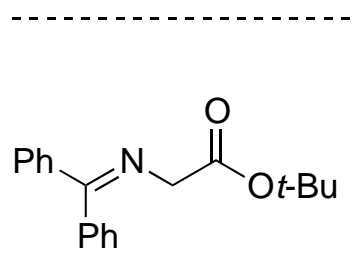

81 $(a R)-79(10 \mathrm{~mol} \%)$

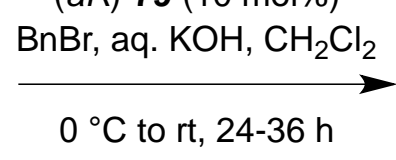

$30-50 \%,<5 \%$ ee

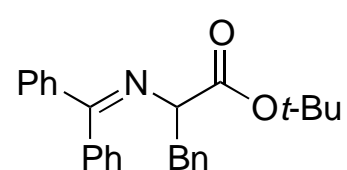

82

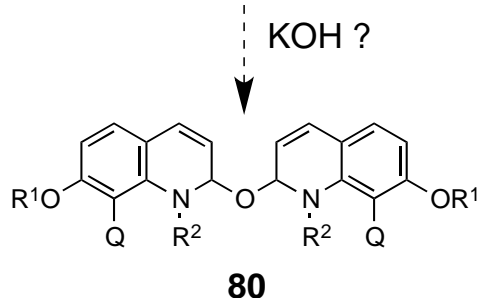

80

Scheme 18. Synthesis of quinolinium salts of $8,8^{\prime}$-diazaBINOL diethers (79) and their evaluation as chiral phase transfer catalysts in the O'Donnell reaction of $\mathbf{8 1}$ to $\mathbf{8 2} .^{51}$

Diesters $78\left(\mathrm{R}^{1}=\mathrm{Bn}, n-\mathrm{C}_{6} \mathrm{H}_{13}\right)$, accessed as illustrated via Williamson ether synthesis from enantioenriched 8,8'-diazaBINOL (3), exhibit excellent solubility and were found to be configurationally stable (i.e., no change in optical rotation upon reflux in toluene for $>12 \mathrm{~h}$ ). Conversion to the requisite monocationic biquinolinium salts 79 was achieved by simple heating in neat excess organohalide (Mel or $\mathrm{BnBr}$ ); further alkylation to give dications was observed upon protracted exposure to the alkylating agent. Biquinolinium salts 79 promoted the desired alkylation of glycine derived Schiff base $\mathbf{8 1}$ to give phenylalanine derivative $\mathbf{8 2}$; however, a detectable level of enantiomeric excess was not discerned in $\mathbf{8 2}$ and progression of the reactions stalled after attainment of only modest yields due to catalyst decomposition. It is likely that irreversible conversion of $N$-alkyl biquinolinium salts $\mathbf{7 9}$ to the so-called 'pseudo-base diethers' $\mathbf{8 0} \mathbf{5}^{57}$ is responsible for their limited turnover numbers. The addition of blocking groups at $C 7\left(/ C 7^{\prime}\right)$ is likely to improve the stability of 79 to nucleophilic attack of hydroxide, albeit the added steric hindrance will make quaternization of the biquinolyl more difficult. 
Other structural changes to this novel class of PTC's, most easily achieved by variations to $\mathrm{R}^{1}$ and $\mathrm{R}^{2}$, could presumably positively impact stereoselectivity. A propos to this last point, the enantioselectivity offered by cinchonidium salt based PTC's is very sensitive to the alkyl group introduced to quaternize the $3^{\circ}$ amine..$^{53}$

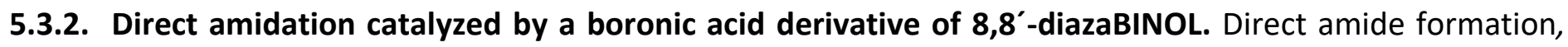
i.e., the formation of amides from amines and carboxylic acids without stoichiometric activation of either coupling partner, is recognized as a significant and important challenge for contemporary organic synthesis. ${ }^{58}$ Some of the most successful catalysts for achieving this aim are based on boronic acids, even quite simple examples, which readily generate competent acylating agents upon a facile dehydration reaction with carboxylic acids. ${ }^{59}$ In a remarkable report, Whiting et al. disclosed that the planar chiral imidazolyl boronic acid 84 is capable of enantioselective amidation via kinetic resolution of racemic chain-branched $1^{\circ}$ amines upon their acylation. ${ }^{60}$ Inspired by this work, an axially chiral analog of 84 (83) was prepared from the 8,8'diazaBINOL-derived triflate (73) previously used as an intermediate en route to phosphine ligand 72 (Scheme 19). The azaBINOL based boronic acid $\mathbf{8 3}$ was found to be only a weakly active catalyst for direct amidation; thus, $\mathbf{8 3}$ is capable of promoting the formation of $N$-benzylbenzamide $(\mathbf{8 7}, \mathrm{R}=\mathrm{H})$ from benzoic acid and benzylamine but not the comparable benzamide $(\mathbf{8 7}, \mathrm{R}=\mathrm{Me})$ from $\alpha$-methylbenzylamine. A more active catalyst would be necessary before an assessment of the potential enantioselectivity for this kind of system can be made.

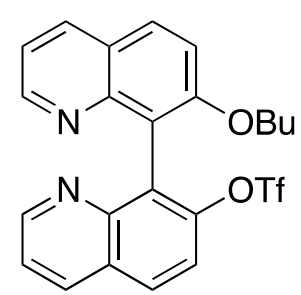

73 (a) $\mathrm{B}_{2} \mathrm{pin}_{2}, \mathrm{PPh}_{3}$, $\mathrm{Pd}\left(\mathrm{PPh}_{3}\right)_{2} \mathrm{Cl}_{2}$ KOAc, dioxane

$100{ }^{\circ} \mathrm{C}, 70 \%$

(b) $1.2 \mathrm{M}$ aq. $\mathrm{HCl}$ THF, rt, $12 \mathrm{~h}$ $53 \%$<smiles>[R]C(N)c1ccccc1</smiles>

85 86 boronic acid

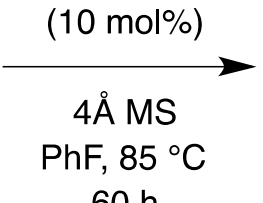<smiles>CCCOc1ccc2cccnc2c1-c1c(Br)ccc2cccnc12</smiles>

83

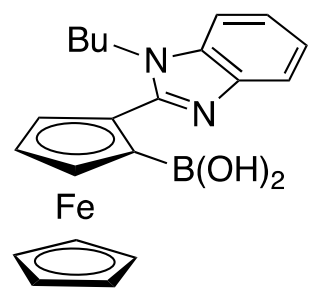

$84 \quad$ Whiting<smiles>[R]C(NC(=O)c1ccccc1)c1ccccc1</smiles>

87

\begin{tabular}{ccl} 
bor. acid & $\mathrm{R}$ & yield $\mathbf{8 7}$ \\
\hline none & $\mathrm{H}$ & $0 \%$ \\
$\mathbf{8 3}$ & $\mathrm{H}$ & $21 \%$ \\
$\mathbf{8 3}$ & $\mathrm{Me}$ & $0 \%$ \\
$\mathbf{8 4}$ & $\mathrm{Me}$ & $21 \% \quad(41 \% \text { ee })^{60}$
\end{tabular}

Scheme 19. Synthesis of an 8,8'-diazaBINOL boronic acid derivative (83) and its application as a catalyst for a direct amidation reaction with comparative data for Whiting's catalyst $\mathbf{8 4} .{ }^{51,60}$

\section{Emerging Biological Activity of AzaBINOLs}

\subsection{Prefatory remarks}

Libraries of compounds designed to be used primarily as chiral ligands and/or organocatalysts for the purpose of enantioselective synthesis are seldom systematically screened for biological activity. This fact is regrettable when given that sources of novel structures are constantly needed by drug discovery efforts and that features present in organocatalysts and ligands that are necessary for their intended function (e.g., chiral scaffolds with few rotatable bonds, metal ion binding sites, $\mathrm{H}$-bond acceptors and donors, sites of high charge density and/or ionization, and zones of steric encumbrance, etc.), could allow for them to engage in meaningful and selective 
interactions with proteinogenic targets implicated in disease amelioration. The polyfunctionality of azaBINOL derivatives, and the ease with which diverse sets of such compounds can be generated, means that this family of compounds is, in principle, particularly well-suited for biological screening efforts. Indeed, many better known biaryl molecules, and especially examples of natural origin, ${ }^{61}$ have shown useful biological activities, including selective anti-HIV activity. ${ }^{62}$ Accordingly, in a collaborative effort, we elected to screen a collection of azaBINOL derivatives against HIV relevant bioassays and in doing so, and as summarized below, a promising lead compound for HIV-1 neutralization that acts against a little explored molecular target was identified. ${ }^{10}$

\subsection{Inhibition of HIV-1 RNase $\mathbf{H}$ activity by an ether derivative of 2'-deoxy-8-azaBINOL}

HIV/AIDS remains a global health epidemic and although modern drug regimens are able to keep viral loads low in infected patients, these treatments are far from ideal, being at once expensive, subject to side-effects, limited in their geographical and socioeconomic group availability, and increasingly threatened by emergence of drug resistance. ${ }^{63}$ Thus, novel therapeutics that act on previously untargeted steps of the viral life-cycle are of great interest. In a triage screen, three 8-azaBINOL derivatives were identified from a modestly sized library of azaBINOL compounds to possess promising activity in a pseudo-typed viral particle single-round infectivity assay (HIVpp) at single-dose concentrations: $\mathbf{8 8 , 8 9}$, and $\mathbf{9 1} .^{10}$ These compounds, in addition to a set of three close-structural analogs including comparable 8,8'-diazaBINOLs (92 and $\mathbf{9 3}$ ), were further evaluated for their $\mathrm{IC}_{50}$ values against HIV-1 particles pseudo-typed with HIV-1 envelope proteins originating from three different HIV-1 strains in TZM-bl cells (the data illustrated for the HXB2 isolate are representative), and then in fullyinfectious, replication competent HIV-1 $1_{\text {LAI }}$ in LC5-RIC cells using the 'EASY-HIT' full viral infection assay system (Table 3) ${ }^{64}$ of the six compounds studied at this level of detail, only the isopropyl ether of 2 -deoxy-8azaBINOL (88) showed consistent low micromolar $I_{50}$ values against HIV-1 while exhibiting a cytotoxicity to efficacy selectivity index $\left(\mathrm{CC}_{50} / \mathrm{IC}_{50}\right)$ in the employed cell types of over $10 .{ }^{10} \mathrm{It}$ is noteworthy that isosteric changes to the structure of $\mathbf{8 8}$, including formally relocating the isopropoxy substituent to the naphthyl-ring (90) and introduction of an additional aromatic-ring bound $\mathrm{N}$-atom (92), result in loss of anti-viral activity.

Table 3. $\mathrm{IC}_{50}$ and $\mathrm{CC}_{50}$ values for the indicated ether (in black) or carbamate (in blue) azaBINOL

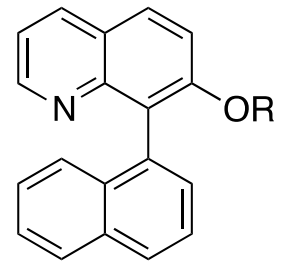

$( \pm)-88$

$(\mathrm{R}=i-\mathrm{Pr}) \quad\left(\mathrm{R}=\mathrm{CONEt}_{2}\right)$

$\mathrm{IC}_{50}(\mathrm{HXB2})$

$\mathrm{CC}_{50}(\mathrm{TZM}-\mathrm{bl})$

$6.7 \pm 0.9$

$68.5 \pm 17.1$

$61.4 \pm 3.3$

$95.0 \pm 13.1$

$$
\begin{aligned}
& \mathrm{IC}_{50}\left(\mathrm{HIV}-1_{\text {LAI }}\right) \\
& \mathrm{CC}_{50}(\mathrm{LC} 5-\mathrm{RIC})
\end{aligned}
$$$$
6.7 \pm 1.4
$$

$24.1 \pm 0.7$

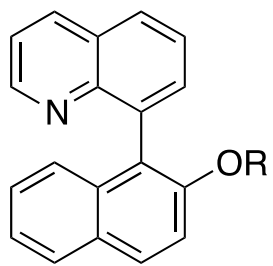

$( \pm)-90$

$(\mathrm{R}=i-\mathrm{Pr}) \quad\left(\mathrm{R}=\mathrm{CONEt}_{2}\right)$

$>100$

$>100$

$12.6 \pm 1.6$

$69.3 \pm 4.9$

$39.5 \pm 1.7$

$50.1 \pm 3.7$

$144.7 \pm 7.7$

$71.4 \pm 2.8$

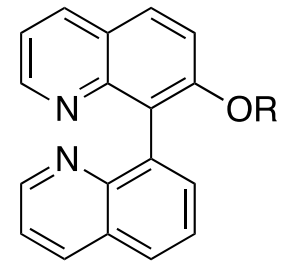

$( \pm)-92$

$( \pm)-93$

$(\mathrm{R}=i-\mathrm{Pr}) \quad\left(\mathrm{R}=\mathrm{CONEt}_{2}\right)$

no effect no effect

no effect no effect

no effect no effect

no effect $382.8 \pm 166.2$

$\mathrm{IC}_{50}$ and $\mathrm{CC}_{50}$ values for the indicated ether (in black) or carbamate (in blue) azaBINOL derivatives are in $\mu \mathrm{M}$ units. Details of appropriate control studies are described in the original publication. ${ }^{10}$ 
Given the promising in vitro anti-HIV activity discovered for $\mathbf{8 8}$, which it was found extended to a multidrug resistant isolate (HIV-1 $\left.1_{\mathrm{V} 13-03413 \mathrm{~B}}\right)^{65}$ extensive mode-of-action studies were undertaken to identify its molecular target. These experiments, which included enzyme inhibition assays for HIV-1 integrase and HIV-1 reverse transcriptase (RT) dual functions (DNA polymerase and RNase $\mathrm{H}$ activity), ${ }^{10}$ revealed that 88 is likely to exert its anti-HIV-1 effect by specific inhibition of RT RNase $\mathrm{H}$ activity via a binding site distinct from that engaged by typical non-nucleoside RT inhibitors (NNRTIs). ${ }^{66}$ Thus, the NNRTI efavirenz and 88 were shown not to compete in their HIV-1 neutralization effects in an HIVpp assay. ${ }^{10}$ Few potential therapeutic agents for the treatment of HIV/AIDS have been identified to date that act by inhibition only of the RNase $\mathrm{H}$ function of the RT enzyme (and including: acyl hydrazones, ${ }^{67}$ vinylogous ureas, ${ }^{68}$ and $\mathrm{cHTCs}^{69}$ ) and so the discovery of 88 is significant. It is speculated that the naphthyl moiety of $\mathbf{8 8}$ binds to a hydrophobic surface present on the RNase $\mathrm{H}$ domain of HIV-1 $\mathrm{RT}^{70}$ leaving the polar substituted quinoline unit to further interact with interior aspects of the protein. The 8,8'-diazaBINOL analog of $\mathbf{8 8}$ (92) lacks the requisite hydrophobic ring-system for effective binding, while the bulkier and more polar naphthyl ring of its regioisomer (90) likely also fails to properly engage with the hydrophobic surface. ${ }^{10}$ In ongoing work, it has been established that $\mathbf{8 8}$ is configurationally stable at rt and that its dextrorotary enantiomeric atropisomer has 3-6 times greater potency for HIV-1 neutralization than the levorotary antipode. ${ }^{71}$ In closing, it should be borne in mind that $8 \mathbf{8}$ is an unoptimized lead compound and that structural modifications are anticipated to result in improved binding affinity for the RNase H domain of the RT enzyme and an overall enhanced HIV-1 neutralization capability.

\section{Conclusion and Outlook}

This account on the chemistry and biology of the azaBINOL-family of compounds illustrates that fundamental research on novel chemical entities, even if initiated for esoteric purposes, will be likely to lead to useful discoveries if the molecular system in question offers something significantly new to be explored. For example, herein, in seeking to access 3,3'-disubstituted 8,8'-diazaBINOL derivatives, the fascinating anionic rearrangements of 6-lithio-8-iodoquinoline 18 were uncovered (Section 2). ${ }^{2}$ Elsewhere, in assessing the configurational stability of azaBINOLs, the fact that the enantiomerization pathway for $8,8^{\prime}$-diazaBINOL (3) is wholly distinct from those of 8 -azaBINOL (2) and BINOL (1) was unexpectedly revealed (Section 3 ). ${ }^{3,9}$ In other work, curiosity about strain-induced basicity led us to discover that the interannular dihedral angles within $8,8^{\prime}$-diazaBINOL derivatives are dependent on $\mathrm{pH}$ (Section 4$),{ }^{5}$ a finding that could have implications for the creation of stimulus responsive extended materials (e.g., MOFs) that incorporate biquinolyls. In the latest research described (Section 6), ${ }^{10}$ a novel HIV-1 neutralization agent that inhibits RNase $\mathrm{H}$ activity of the dual function reverse transcriptase (RT) enzyme, O-isopropyl-2'-deoxy-8-azaBINOL (88), was identified from a library of azaBINOLs. Isosteres of ether $\mathbf{8 8}$ lack anti-viral activity and its bioactivity is dependent on absolute configuration; taken together, these facts indicate that the promising lead compound $\mathbf{8 8}$ engages in specific/directional interactions with its biological target and therefore meaningful optimization of the structure for better efficacy should be possible.

It is fair to acknowledge that the azaBINOL derivatives examined so far for reaction catalysis (all based on $8,8^{\prime}$-diazaBINOL) have not delivered an acceptable level of enantioselectivity (Section 5). However, given that non-canonical reactivity modes for biaryl catalysts were studied, and that structural optimization efforts were not pursued, the poor stereocontrol encountered is perhaps not surprising and certainly it does not preclude more effective azaBINOL based catalysts being identified in future. Accordingly, further investigations of azaBINOL derivatives in reaction catalysis are warranted, including research on as yet unexplored azaBINOL 
chemotypes (e.g., $\mathrm{N}$-oxides, 5-dialkylamino substituted etc.) and incorporating molecules based on 8-azaBINOL (2), which will offer solubility and configurationally stability advantages over 8,8'-diazaBINOL (3) derivatives. A powerful new method for the resolution of axially chiral azacyclic biaryls by enantioselective transfer hydrogenation, already successfully demonstrated for 8-azaBINOL derivatives in the first report of this process by Zhou et al., ${ }^{72}$ complements existing approaches to access non-racemic azaBINOLS and will help to facilitate future studies.

Finally, notwithstanding the welcome discovery of an interesting organocatalysis mode for the silylcyanation of $C=X$ bonds by bissulfonamide 5 (Section 5.1 ), ${ }^{7}$ it will not have escaped the notice of an attentive reader, that the validity of the original premise that motivated instigation of the azaBINOL project, namely bond formation catalyzed via the agency of a frustrated LA/LB pair manifested across a biaryl cleft (Figure 2), has yet to be tested. Before such a plan is revisited and truly evaluated, now with the benefit of hindsight, the speciation of metal residues by azaBINOL derivatives needs to be properly understood, beginning with experiments to probe the basic coordination chemistry of 8-azaBINOL (2), and then progressing to $8,8^{\prime}$-diazaBINOL (3) before more elaborate ligand systems, such as bissulfonamide $\mathbf{5}$, are tackled.

\section{Acknowledgements}

The Author thanks his former graduate and undergraduate student coworkers who conducted the research summarized in this account; first and foremost, Selena Milicevic Sephton (née S. D. Milicevic), who made the seminal contributions to azaBINOL chemistry, and then those who followed: Chao Wang, Darrin M. Flannigan, Zhenhua Wu, Somdev Banerjee, Brian E. Riggs, and Cynthia A. Cedeño. Professor Sandra Loesgen (University of Florida, Saint Augustine, FL, USA) and her student Ross D. Overacker are gratefully acknowledged for a fruitful and stimulating collaboration that led to the discovery of the anti-HIV-1 activity of azaBINOL derivative 88 . Dr. Lev N. Zakharov (University of Oregon, Eugene, OR, USA) is thanked for conducting countless single crystal Xray diffraction analyses that provided profound structural insights. Finally, Professor Dr. Till Opatz (Johannes Gutenburg Universität, Mainz, Germany) is thanked for graciously hosting the Author at JGU-Mainz while this account was being written (Sept.-Nov. 2019).

\section{Author's Biography}

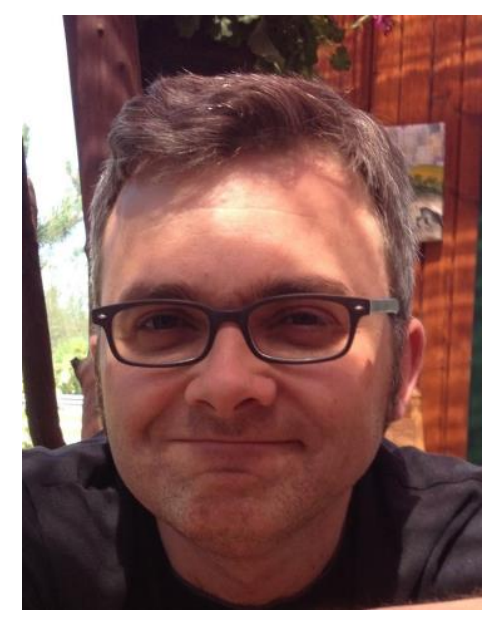

Paul R. Blakemore was born in East London in 1973. He obtained B.Sc. degrees in Chemistry and Mathematics from the University of Southampton (1995) and earned a Ph.D. degree from the University of Glasgow (1999) 
for research on sulfone-based olefination methods with Professor Philip J. Kocienski. Following post-doctoral work on the target-directed synthesis of complex natural product molecules with Professor James D. White at Oregon State University (USA), he began his independent career as a Royal Society University Research Fellow at the University of Leeds (UK) in 2001. Since returning to Oregon in 2005, Dr. Blakemore has been a faculty member of the Department of Chemistry at OSU where he is currently Professor of Chemistry. In addition to azaBINOL chemistry, his research is focused on the development of new methods for the absolute control of molecular constitution and stereochemistry by using enantioenriched main-group chiral carbenoids as generic synthons for the synthesis of polysubstituted alkyl domains and carbon-carbon double bonds. Dr. Blakemore is the author of numerous research/review articles and book chapters and he currently serves on the editorial board of Organic Reactions (since 2018).

\section{References}

1. Brunel, J. M. Chem. Rev. 2005, 105, 857-898.

https://doi.org/10.1021/cr040079g

2. Blakemore, P. R.; Kilner, C.; Milicevic, S. D. J. Org. Chem. 2005, 70, 373-376.

https://doi.org/10.1021/jo0482581

3. Blakemore, P. R.; Kilner, C.; Milicevic, S. D. J. Org. Chem. 2006, 71, 8212-8218.

https://doi.org/10.1021/jo061608e

4. Blakemore, P. R.; Milicevic, S. D.; Zakharov, L. N. J. Org. Chem. 2007, 72, 9368-9371.

https://doi.org/10.1021/jo701611u

5. Blakemore, P. R.; Milicevic, S. D.; Perera, H.; Shvarev, A.; Zakharov, L. N. Synthesis 2008, 2271-2277.

https://doi.org/10.1055/s-2008-1078448

6. Wang, C.; Flanigan, D. M.; Zakharov, L. N.; Blakemore, P. R. Org. Lett. 2011, 13, 4024-4027. https://doi.org/10.1021/ol201539d

7. Milicevic-Sephton, S.; Wang, C.; Zakharov, L. N.; Blakemore, P. R. Eur. J. Org. Chem. 2012, 3249-3260. https://doi.org/10.1002/ejoc.201200333

8. Wu, Z.; Wang, C.; Zakharov, L. N., Blakemore, P. R. Synthesis 2014, 46, 678-685. https://doi.org/10.1055/s-0033-1340519

9. Banerjee, S.; Riggs, B. E.; Zakharov, L. N.; Blakemore, P. R. Synthesis 2015, 47, 4008-4016. https://doi.org/10.1055/s-0035-1560640

10. Overacker, R. D.; Banerjee, S.; Neuhaus, G. F.; Milicevic-Sephton, S.; Herrmann, A.; Strother, J. A.; BrackWerner, R.; Blakemore, P. R.; Loesgen, S. Bioorg. Med. Chem. 2019, 27, 3595-3604.

https://doi.org/10.1016/j.bmc.2019.06.044

11. Rowlands, G. J. Tetrahedron 2001, 57, 1865-1882.

https://doi.org/10.1016/S0040-4020(01)00057-6

12. Hamashima, Y.; Sawada, D.; Kanai, M.; Shibasaki, M. J. Am. Chem. Soc. 1999, 121, 2641-2642. https://doi.org/10.1021/ja983895c

13. Casas, J.; Nájera, C.; Sansano, J. M.; Saá, J. M. Org. Lett. 2002, 4, 2589-2592.

https://doi.org/10.1021/ol0262338

14. Godard, A.; Robin, Y.; Quéguiner, G. J. Organomet. Chem. 1987, 336, 1-12.

https://doi.org/10.1016/0022-328X(87)87152-8

15. Sibi, M. P.; Snieckus, V. J. Org. Chem. 1983, 48, 1935-1937. 
https://doi.org/10.1021/jo00159a040

16. Myers, A. G.; Yang, B. H.; Chen, H.; McKinstry, L.; Kopecky, D. J.; Gleason, J. L. J. Am. Chem. Soc. 1997, $119,6496-6511$.

https://doi.org/10.1021/ja970402f

17. Whisler, M. C.; MacNeil, S.; Snieckus, V.; Beak, P. Angew. Chem., Int. Ed. 2004, 43, 2206-2225. https://doi.org/10.1002/anie.200300590

18. Bunnett, J. F. Acc. Chem. Res. 1972, 5, 139-147.

https://doi.org/10.1021/ar50052a004

19. Xuan, D. D. Curr. Org. Synth. 2019, 16, 671-708.

https://doi.org/10.2174/1570179416666190719112423

20. Tokuyama, H.; Sato, M.; Ueda, T.; Fukuyama, T. Heterocycles 2001, 54, 105-108.

https://doi.org/10.3987/COM-00-S(I)63

21. Dick, A. R.; Hull, K. L.; Sanford, M. S.. J. Am. Chem. Soc. 2004, 126, 2300-2301.

https://doi.org/10.1021/ja031543m

22. Daugulis, O.; Zaitsev, V. G. Angew. Chem., Int. Ed. 2005, 44, 4046-4048.

https://doi.org/10.1002/anie.200500589

23. Colon, I.; Kelsey D. R. J. Org. Chem. 1986, 51, 2627-2637.

https://doi.org/10.1021/jo00364a002

24. Miyaura, N.; Suzuki, A. Chem. Rev. 1995, 95, 2457-2483.

https://doi.org/10.1021/cr00039a007

25. Ghosh, B.; Biswas, A.; Chakraborty, S.; Samanta, R. Chem. Asian J. 2018, 13, 2388-2392.

https://doi.org/10.1002/asia.201800462

26. Fabbri, D.; Delogu, G.; De Lucchi, O. J. Org. Chem. 1995, 60, 6599-6601.

https://doi.org/10.1021/jo00125a057

27. Kazlauskas, R. J. J. Am. Chem. Soc. 1989, 111, 4953-4959.

https://doi.org/10.1021/ja00195a059

28. Milicevic, S. D. Atropisomeric 8,8'-Biquinolyl Derivatives: Synthesis, Properties and Applications. Ph. D.

Dissertation, Oregon State University, Corvallis, OR, June 2008.

https://ir.library.oregonstate.edu/concern/graduate thesis or dissertations/b2773z53h

29. Drago, C.; Caggiano, L.; Jackson, R. F. W. Angew. Chem., Int. Ed. 2005, 44, 7221-7223.

https://doi.org/10.1002/anie.200503046

30. Mason, S. F.; Seal, R. H.; Roberts, D. R. Tetrahedron 1974, 30, 1671-1682.

https://doi.org/10.1016/S0040-4020(01)90689-1

31. Rickhaus, M.; Jundt, L.; Mayor, M. Chimia 2016, 70, 192-202.

https://doi.org/10.2533/chimia.2016.192

32. Laidler, K. J.; King, M. C. J. Phys. Chem. 1983, 87, 2657-2664.

https://doi.org/10.1021/j100238a002

33. Davoren, J. E.; Bundesmann, M. W.; Yan, Q. T.; Collantes, E. M.; Mente, S.; Nason, D. M.; Gray, D. L. ACS Med. Chem. Lett. 2012, 3, 433-435.

https://doi.org/10.1021/ml2003108

34. Meca, L.; Reha, D.; Havlas, Z. J. Org. Chem. 2003, 68, 5677-5680.

https://doi.org/10.1021/jo034344u 
35. Kyba, E. P.; Gokel, G. W.; de Jong, F.; Koga, K.; Sousa, L. R.; Siegel, M. G.; Kaplan, L.; Sogah, G. D. Y.; Cram, D. J. J. Org. Chem. 1977, 42, 4173-4184.

https://doi.org/10.1021/jo00862a001

36. Xiao, J.; Loh, T.-P. Org. Lett. 2009, 11, 2876-2879.

https://doi.org/10.1021/ol900790z

37. Kitamura, M.; Fukuma, H.; Kobayashi, M.; Okayama, S.; Okauchi, T. J. Org. Chem. 2016, 81, 3956-3960. https://doi.org/10.1021/acs.joc.6b00534

38. Alder, R. W.; Bowman, P. S.; Steele, W. R. S.; Winterman, D. R. J. Chem. Soc., Chem. Commun. 1968, 723724.

https://doi.org/10.1039/C19680000723

39. Alder, R. W. Chem. Rev. 1989, 89, 1215-1223.

https://doi.org/10.1021/cr00095a015

40. Staab, H. A.; Zirnstein, M. A.; Krieger, C. Angew. Chem., Int. Ed. Engl. 1989, 28, 86-88. https://doi.org/10.1002/anie.198900861

41. Platt, J. R. J. Chem. Phys. 1949, 17, 484-495.

https://doi.org/10.1063/1.1747293

42. Hall, H. K. J. Am. Chem. Soc. 1957, 79, 5441-5444.

https://doi.org/10.1021/ja01577a030

43. Brunel, J.-M.; Holmes, I. P. Angew. Chem., Int. Ed. 2004, 43, 2752-2778.

https://doi.org/10.1002/anie.200300604

44. Akiyama, T.; Itoh, K.; Fuchibe, K. Adv. Synth. Cat. 2006, 348, 999-1010.

https://doi.org/10.1002/adsc.200606074

45. Zuend, S. J.; Jacobsen, E. N. J. Am. Chem. Soc. 2007, 129, 15872-15883.

https://doi.org/10.1021/ja0735352

46. North, M.; Omedes-Pujol, M.; Williamson, C. Chem. Eur. J. 2010, 16, 11367-11375.

https://doi.org/10.1002/chem.201001078

47. Berthod, M.; Mignani, G.; Woodward, G.; Lemaire, M. Chem. Rev. 2005, 105, 1801-1836. https://doi.org/10.1021/cr040652w

48. Alcock, N. W.; Brown, J. M.; Hulmes, D. I. Tetrahedron: Asymmetry 1993, 4, 743-756.

https://doi.org/10.1016/S0957-4166(00)80183-4

49. Uozumi, Y.; Hayashi, T. J. Am Chem. Soc. 1991, 113, 9887-9888.

https://doi.org/10.1021/ja00026a044

50. Yin, J.; Buchwald, S. L. A J. Am. Chem. Soc. 2000, 122, 12051-12052.

https://doi.org/10.1021/ja005622z

51. Wang. C. Synthesis and Catalytic Applications of Derivatives of 7,7'-Dihydroxy-8,8'-biquinolyl (azaBINOL). Ph. D. Dissertation, Oregon State University, Corvallis, OR, June 2013.

https://ir.library.oregonstate.edu/concern/graduate thesis or dissertations/00000222f

52. Ooi, T.; Maruoka, K. Angew. Chem., Int. Ed. 2007, 46, 4223-4266.

https://doi.org/10.1002/anie.200601737

53. O'Donnell, M. J. Tetrahedron 2019, 75, 3667-3696.

https://doi.org/10.1016/i.tet.2019.03.029

54. Ooi, T.; Kameda, M.; Maruoka, K. J. Am. Chem. Soc. 1999, 121, 6519-6520.

https://doi.org/10.1021/ja991062w 
55. Kaneko, S.; Kumatabara, Y.; Shirakawa, S. Org. Biomol. Chem. 2016, 14, 5367-5376. https://doi.org/10.1039/c5ob02446c

56. Zhu, Y. H.; Lou, H.; Lu, P.; Liu, J. G.; Zheng, X. M. Chin. Chem. Lett. 2002, 13, 919-920.

57. Cooksey, C. J.; Johnson, M. D. J. Chem. Soc. B 1968, 1191-1197. https://doi.org/10.1039/J29680001191

58. Monks, B. M.; Whiting, A. Direct Amide Formation Avoiding Poor Atom Economy Reagents. In Sustainable Catalysis, Eds. Dunn, P. J.; Hii, K. K.; Krische, M. J.; Williams, M. T. John Wiley \& Sons, Hoboken, NJ, 2013, pp. 89-110. https://doi.org/10.1002/9781118354520.ch05

59. Charville, H.; Jackson, D.; Hodges, G.; Whiting, A. Chem. Commun. 2010, 46, 1813-1823. https://doi.org/10.1039/B923093A

60. Arnold, K.; Davies, B.; Hérault, D; Whiting, A. Angew. Chem., Int. Ed. 2008, 47, 2673-2676. https://doi.org/10.1002/anie.200705643

61 Bringmann, G.; Gulder, T.; Gulder, T. A. M.; Breuning, M Chem. Rev. 2011, 111, 563-639. https://doi.org/10.1021/cr100155e

62. Boyd, M. R.; Hallock, Y. F.; Cardellina, J. H.; Manfred, K. P.; Blunt, J. W.; McMahon, J. B.; Buckheit, R. W.; Bringmann, G.; Schäffer, M.; Cragg, G. M.; Thomas, D. W.; Jato, J. G. J. Med. Chem. 1994, 37, 1740-1745. https://doi.org/10.1021/jm00038a003

63. Pham, Q. D.; Wilson, D. P.; Law, M. G.; Kelleher, A. D.; Zhang, L. AIDS 2014, 28, 2751-2762. doi: 10.1097/QAD.0000000000000494

64. Kremb, S.; Helfer, M.; Heller, W.; Hoffmann, D.; Wolff, H.; Kleinschmidt, A.; Cepok, S.; Hemmer, B.; Durner, J.; Brack-Werner, R. Antimicrob. Agents Chemother. 2010, 54, 5257-5268. doi: 10.1128/AAC.00515-10

65. Wei, X.; Decker, J. M.; Liu, H.; Zhang, Z.; Arani, R. B.; Kilby, J. M.; Saag, M. S.; Wu, X.; Shaw, G. M.; Kappes, J. C.. Antimicrob. Agents Chemother. 2002, 46, 1896-1905.

DOI: 10.1128/AAC.46.6.1896-1905.2002

66. Namasivayam, V.; Vanangamudi, M.; G. Kramer, V. G.; Kurup, S.; Zhan, P.; Liu, X.; Kongsted, J.; Byrareddy, S. N. J. Med. Chem. 2019, 62, 4851-4883.

https://doi.org/10.1021/acs.jmedchem.8b00843

67. Himmel, D. M.; Sarafianos, S. G.; Dharmasena, S.; Hossain, M. M.; McCoy-Simandle, K.; Ilina, T.; Clark Jr, A. D.; Knight, J. L.; Julias, J. G.; Clark, P. K. ACS Chem. Biol. 2006, 1, 702-712. https://doi.org/10.1021/cb600303y

68. Chung, S.; Wendeler, M.; Rausch, J. W.; Beilhartz, G.; Gotte, M.; O'Keefe, B. R.; Bermingham, A.; Beutler, J. A.; Liu, S.; Zhuang, X. H. Antimicrob. Agents Chemother. 2010, 54, 3913-3921.

DOI: 10.1128/AAC.00434-10

69. Massari, S.; Corona, A.; Distinto, S.; Desantis, J.; Caredda, A.; Sabatini, S.; Manfroni, G.; Felicetti, T.; Cecchetti, V.; Pannecouque, C. J. Enzyme Inhib. Med. Chem. 2019, 34, 55-74. https://doi.org/10.1080/14756366.2018.1523901

70 Kankanala, J.; Kirby, K. A.; Liu, F.; Miller, L.; Nagy, E.; Wilson, D. J.; Parniak, M. A.; Sarafianos, S. G.; Wang, Z. H. J. Med. Chem. 2016, 59, 5051-5062. https://doi.org/10.1021/acs.jmedchem.6b00465

71. Cedeño, C. A.; Overacker, R. D.; Loesgen, S.; Blakemore, P. R. unpublished results. 
72. Wang, J.; Chen, M.-W.; Ji, Y.; Hu, S.-B.; Zhou, Y.-G. J. Am. Chem. Soc. 2016, 138, 10413-10416. https://doi.org/10.1021/jacs.6b06009

This paper is an open access article distributed under the terms of the Creative Commons Attribution (CC BY) license (http://creativecommons.org/licenses/by/4.0/ 